\title{
Gamma ray attenuation in the soils of Northern Ireland, with special reference to peat
}

David Beamish

British Geological Survey, Keyworth, Nottingham, NG12 5GG, UK.

Corresponding author:

David Beamish

British Geological Survey, Keyworth, Nottingham, NG12 5GG, UK

Email: dbe@bgs.ac.uk

Tel: +44(0)1159363432

\section{Keywords:}

Gamma-ray; Soil; Bedrock; Airborne; Attenuation; Moisture; Peat

Beamish, D., 2013. Gamma ray attenuation in the soils of Northern Ireland, with special reference to peat. Journal of Environmental Radioactivity, 115, 13-27.

http://dx.doi.org/10.1016/j.jenvrad.2012.05.031 


\section{ABSTRACT}

This study considers gamma ray attenuation in relation to the soils and bedrock of Northern Ireland using simple theory and data from a high resolution airborne survey. The bedrock is considered as a source of radiogenic material acting as parent to the soil. Attenuation in the near-surface is then controlled by water content in conjunction with the porosity and density of the soil cover. The Total Count radiometric data together with 1:250k mapping of the soils and bedrock of Northern Ireland are used to perform statistical analyses emphasising the nature of the low count behaviour.

Estimations of the bedrock response characteristics are improved by excluding areas covered by low count soils (organic/humic). Equally, estimations of soil response characteristics are improved by excluding areas underlain by low count bedrock (basalt). When the spatial characteristics of the soilclassified data are examined in detail, the low values form spatially-coherent zones (natural clusters) that can potentially be interpreted as areas of increased water content for each soil type. As predicted by theory, the highest attenuation factors are associated with the three organic soil types studied here. Peat, in particular, is remarkably skewed to low count behaviour in its radiometric response. Two detailed studies of blanket bogs reveal the extent to which peat may be mapped by its radiometric response while the intra-peat variations in the observed response may indicate areas of thin cover together with areas of increased water content. 


\section{Introduction}

Airborne gamma spectrometer measurements form a significant component of the recent multiparameter geophysical data sets acquired for exploration, environmental and baseline studies in the UK (Beamish and Young, 2009). The radiometric data have been used across a range of environmental assessments that include regional and local scale studies of natural and man-made distributions of excess concentrations (Lahti and Jones, 2003). The high spatial resolution data (200 $\mathrm{m}$ line spacing at $\sim 56 \mathrm{~m}$ elevation) have also been used in a number of soil-related studies. The uranium (U) data are now widely applied to radon mapping (Appleton et al., 2008; Appleton et al., 2011). The use of data from multiple surveys allowed the distribution of caesium $\left({ }^{137} \mathrm{Cs}\right)$ across northern Britain to be studied in detail (Scheib and Beamish, 2010). Across the soils of eastern England, the study by Rawlins et al. (2007) indicated that the radiometric signals are useful for making thematic maps of soil and confirmed that a large proportion of the thorium (Th) and potassium (K) signals can be accounted for by parent material. Additionally, the airborne data ( $\mathrm{K}$ signal) from Northern Ireland (NI) were used to study methods for improving current estimates of soil organic carbon (SOC) (Rawlins et al., 2009). The use of gamma ray attenuation (considered here) in conjunction with other airborne geophysical data (conductivity) was discussed in relation to the characterisation of wetland sites in North Wales by Beamish and Farr (2011).

Generally, environmental airborne radiometric studies employ one or more of the main, naturally occurring radioelement estimates ( $\mathrm{K}, \mathrm{Th}$ and $\mathrm{U})$, together with their ratios, to establish relationships that have potential applications in areas such as soil mapping (e.g. Cook et al., 1996). Some baseline assessments of radiometric response as a function of bedrock (parent material) and/or soil type exist (Dickson and Scott, 1997; Beamish and White, 2011). Airborne studies differ from groundbased measurements in that the data are acquired uniformly and thus may encounter a range of water bodies including the sea. The attenuation of radiometric signal due to water or soil moisture is well-established (Carroll, 1981) and while studies of airborne data sets may note or discard unwanted attenuation features due to water or water-content, extensive studies of the radiometric signal attenuation levels in single baseline (meaning one-off) survey data sets are rare. Repeat (timelapse) airborne radiometric surveys have the capability to provide assessments of snow-water equivalent (SWE) and/or soil moisture by estimation of the variation in attenuation, from a known calibrated baseline, due to varying water content (Caroll, 1987; Loijens, 1980). The ability to assess attenuation levels from one-off survey data is considered here. Ideally a baseline needs to be established in order to examine both enhanced and attenuated levels of radiometric signals. Usually the controlling factor when establishing radiometric signal levels would be that associated with the parent material. Each rock type, with an associated geochemistry, is assumed to contain a distribution of primordial radionuclides that were incorporated during the formation of the planet (IAEA, 2003).

When considering the amplitude of the radiometric response observed on, or above, the surface the simplest conceptual vertical model comprises two layers above bedrock. In the general case, the two upper layers would be defined by soil and superficial (Quaternary) deposits whose radiogenic content is assumed to be derived from the parent bedrock material. Whatever the near-surface 
material (i.e. the presence/absence and thicknesses of the 2 layers) the observed response will be derived from a given radiometric source concentration (assumed vertically uniform in the first instance) that is primarily obtained from a shallow subsurface zone (often $<0.5 \mathrm{~m}$ ). This zone is largely associated with soil cover and thus it is the properties of the soil that usually govern the radiometric decay (a standard exponential function) within a given material.

The majority of descriptions of gamma-ray attenuation found in the literature do not specifically include soils and soil properties. Radiometric attenuation in these materials is reviewed here and the existing theory is recast in more familiar terms of soil density, porosity and water saturation (in the absence of soil, other equivalent material properties will still apply). This allows two critical analyses of generic soils (i.e. type soils) to be developed. The first relates to the main depth interval that contributes to the observed response. The second analysis relates to the type-behaviour of uniform soils largely as a function of water saturation with density and porosity acting as secondary variables.

Here we use the NI survey data alongside two main 1:250,000 independent mappings of soil and bedrock to investigate levels of response attenuation. Secondary information on response enhancements is also obtained. Although, as part of the classification procedures, the behaviour of individual radioelements ( $\mathrm{K}$, Th and $\mathrm{U}$ ) was obtained, the most useful summary attenuation measurement is the Total Count (TC) which, being a spectral summation, also offers enhanced signal/noise when examining low amplitude behaviour.

The classified TC data are coupled to variations in both intrinsic bedrock radiogenic concentrations and very-near surface (e.g. soil) material properties. No ground control measurements of general soil properties (particularly degree of water saturation, or soil moisture) are available at the 1:250,000 mapping scale used here. In order to extend the large-scale geostatistical analysis to the practical level, two case studies of attenuation behaviour across peat areas are considered. Peats, in particular, have a high sensitivity to soil moisture content. The first study considers the largest area of intact peat bog in Northern Ireland which is underlain by low response basalt bedrock. The second study area contains the second largest peat bog in Northern Ireland underlain by moderately radiogenic Carboniferous sandstones, limestones and mudstones. The case studies serve to demonstrate the manner in which the airborne soil classified radiometric data can provide a framework for further ground-based studies of soil moisture.

\section{Theory}

\subsection{Gamma ray attenuation}

The interaction of gamma rays with matter and the properties of airborne gamma-ray spectra are discussed by Minty (1967). The shape of the gamma-ray flux spectrum at airborne heights is a function of the concentration and geometry of the source radioelements, the thickness of any nonradioactive overburden, and the height of the detector above ground.

A common approach to the modelling of gamma-ray fields is a semi-empirical one based on monoenergetic (unscattered) radiation. The exponential absorption that characterises the passage 
of monochromatic electromagnetic radiation through a homogenous material is given by the BeerLambert Law (Davisson, 1965S) as:

$I=I_{0} \exp (-\mu x)$

Where $I_{0}$ is the initial radiation intensity. Intensity is usually described as a pulse count rate in photon detection systems. The linear attenuation coefficient $(\mu)$ of the material is an intrinsic property of each material and would usually be associated with a specific element of given atomic number. The mass attenuation coefficient $\left(\mu_{m}\right)$ of the material is given by:

$\mu_{m}=\mu / \rho$

where $\rho$ is density. Equation (1) may then be expressed using the mass attenuation coefficient and the density of the material. Mass attenuation coefficients for air, water and concrete as a function of photon energy are tabulated by Minty (1967) across the energy range from 0.01 to $3 \mathrm{MeV}$. The attenuation coefficient is observed to decrease with increasing energy. At energies above $1 \mathrm{MeV}$, the half-thicknesses (thickness of material that reduces the intensity to half its initial value) range from 84 to $150 \mathrm{~m}$ (air), 9.8 to $17.5 \mathrm{~cm}$ (water) and 4.35 to $7.6 \mathrm{~cm}$ (concrete) (Grasty, 1979; Minty, 1967).

Løvberg (1984) discusses the general principles of gamma-ray attenuation and the effect of moisture content of materials. It is noted that Compton scattering (incoherent scattering) is the main significant attenuation interaction at the energies discussed here. In such circumstances the linear attenuation coefficient $\mu$ is proportional to the total number of electrons per unit volume of the material. Løvberg (1984) indicates that all elements with an atomic number less than 30 will have comparable mass attenuation coefficients. In the absence of water, soil, superficial and bedrock materials will have comparable attenuation coefficients at a given source concentration.

Hydrogen supplied to the material as absorbed or free water (e.g. pore water) then generates an additional attenuation provided by the additional electron content. Løvberg (1984) then establishes expressions for the gamma ray reduction from source material containing pore water. The expressions, discussed later, are based on the fact that water has 1.11 times as many electrons as most materials including soils (Grasty, 1997).

\subsection{Soils}

Soils are characterised as a three-phase system comprising solid, water and air. In the case of such mixtures it is necessary to replace the attenuation (decay) coefficients $(\mu)$ in equation (1) by a summation: $\Sigma_{i} \mu_{i} x_{i}$ where i enumerates the coefficients of each material (Endrestol, 1980). Rewriting equation (1) for a 3-phase soil gives:

$I=I_{0} \exp -\left(\mu_{s} \theta_{s} x+\mu_{w} \theta_{w} x+\mu_{a} \theta_{a} x\right)$

where $\theta$ is the fraction of each component and subscripts $s, w$ and a refer to soil, water and air respectively and $\theta_{\mathrm{s}}+\theta_{\mathrm{s}}+\theta_{\mathrm{s}}=1$ for a unit volume.

Within the general area of soil science, a particular soil may be characterised by the volumes and/or weights of the three materials. Total volume $(\mathrm{V})$ is the sum of solid (soil) volume $\left(\mathrm{V}_{\mathrm{s}}\right)$, water volume 
$\left(V_{w}\right)$ and air volume $\left(V_{a}\right)$. Within this framework, porosity $(\varnothing)$ is defined as the volume of voids $\left(V_{w}+\right.$ $V_{a}$ ) divided by the total volume $(\mathrm{V})$ :

$\varnothing=\left(V_{w}+V_{a}\right) / V$

The degree of saturation $(S)$ is defined as the volume of water $\left(V_{w}\right)$ divided by the volume of voids $\left(V_{w}+V_{a}\right):$

$S=V_{w} /\left(V_{w}+V_{a}\right)$

Both quantities are dimensionless ratios but are commonly expressed as percentages. Using these standard definitions and by setting the total volume $(\mathrm{V})$ to unity to obtain the three required fractional contributions, we find:

$\theta_{s}=(1-\varnothing)$

$\theta_{\mathrm{w}}=\mathrm{S} \varnothing$

$\theta_{\mathrm{a}}=\varnothing(1-\mathrm{S})$

If we consider a vertically uniform thick surface layer (a half-space), a simple model of attenuation is provided by substitution of equations (6), (7) and (8) into equation (3). Multiple layer models can also be constructed by a summation procedure.

Soils are complex materials with a wide range of mineralogies giving rise to a range of atomic numbers across the solid phase. Although the mass attenuation coefficients of some soils have been obtained in laboratory experiments (Pires et al., 2006), the experiments tend to be carried out at energies much lower than those considered here. In the absence of general information as a function of soil type, we first consider representative attenuation coefficients for materials used in previous forward simulation studies (Minty, 1967; Billings and Hovgaard, 1999). The published mass attenuation coefficients for the potassium peak energy range $(1.46 \mathrm{MeV})$ used here are 0.0528 $\mathrm{cm}^{2} / \mathrm{g}$ (soil), $0.0526 \mathrm{~cm}^{2} / \mathrm{g}$ (air) and $0.0572 \mathrm{~cm}^{2} / \mathrm{g}$ (water). Following the previous discussion on the relative insensitivity of the solid phase mass attenuation coefficient to material type, we proceed by retaining the stated attenuation value for all the solid phase components studied here.

The specific soils across the study area are discussed later; however, with regard to the general assessment of soil density, it is usual to consider mineral and organic soils as two separate and limiting categories. Mineral soils (e.g. those with no organic horizon, brown earths, podzols, gleys and rankers) form a separate class to organic soils such as peat with an intermediate category described as organo-mineral soils (i.e. those with an organic horizon overlying mineral subsoil, humic gleys, humic rankers and organic alluvium).

In recent times the increased need for assessments of soil carbon has provided increased knowledge of soil density variations as a function of soil type particularly in the upper $50 \mathrm{~cm}$. The uncertainties in bulk density feed through to estimates of carbon stocks since they require a combined knowledge of bulk density and soil organic carbon. Recent studies of UK soils by Bradley et al. (2005) and for 
Irish soils by Kiely et al. (2010) indicate the range of values encountered. While acknowledging that variations with depth exist, it is possible to provide some bounding values with regard to establishing generic soil behaviour. Most mineral soils in the UK are found to have dry bulk densities in the range 1.1 to $1.6 \mathrm{~g} / \mathrm{cm}^{3}$ (Bradley et al., 2005). The situation with regard to humic soils, including peat, is more complex. Bounding values of peat density in the study of Kiely et al. (2010) were 0.05 to 0.25 g. $\mathrm{cm}^{3}$ across the depth range from surface to $50 \mathrm{~cm}$. A similar range of values was encountered in a study of afforested peatlands in Ireland (Wellock et al., 2011). A standard reference vertical peat profile is also provided by Clymo (1992) and this is used here when assigning dry bulk density values. The reference model displays dry density values down to $0.03 \mathrm{~g} / \mathrm{cm}^{3}$ in the uppermost layer (the acrotelm) which then increase to $0.12 \mathrm{~g} / \mathrm{cm}^{3}$ in the deeper catotelm layer $(>12 \mathrm{~cm})$. Here we employ a uniform value of $0.1 \mathrm{~g} / \mathrm{cm}^{3}$ for simplicity.

\subsection{Attenuation in soils}

In order to specify the fractional components of a soil we use the porosity and degree of saturation discussed above. It is then necessary to consider limiting values of these parameters for both mineral and organic soils. In the case of mineral soils we assume some degree of water saturation in the near-surface material (e.g. temperate latitudes) and set water saturation at $20 \%$ in a material with $40 \%$ porosity. Two reference 'mineral soil' attenuation curves are shown in Figure 1a for soils having bulk densities of 1.1 and $1.6 \mathrm{~g} / \mathrm{cm}^{3}$. The most rapid attenuation curve is obtained using the higher density soil and it can be seen $90 \%$ of the observed signal (at the surface) is obtained from the upper $40 \mathrm{~cm}$. When the soil bulk density decreases to $1.1 \mathrm{~g} / \mathrm{cm}^{3}$, the $90 \%$ threshold increases to a depth of $60 \mathrm{~cm}$. These values are in accord with many of the statements regarding the depth contribution of gamma ray flux in the literature (e.g. Minty, 1967).

We next consider organic soils, that are distinguished by much lower bulk densities, higher porosities and can comprise $>90 \%$ water content when wet. As noted previously we employ a uniform value of bulk density of $0.1 \mathrm{~g} / \mathrm{cm}^{3}$ for simplicity. A peat porosity value of $80 \%$ is taken as typical for the depth range from 0 to $100 \mathrm{~cm}$ following the study of Kechavarzi et al. (2010). Figure 1a shows a 'wet peat' attenuation curve for $80 \%$ porosity with $80 \%$ water saturation. This curve indicates that the $90 \%$ threshold value is obtained at a depth of $60 \mathrm{~cm}$. The 'dry peat' attenuation curve shown in Figure 1a is obtained again using $80 \%$ porosity but with only $20 \%$ water saturation. The very low density and low water content provide an attenuation curve that would extend the $90 \%$ threshold value to several metres.

We also consider a uniform bedrock (i.e. no soil cover) comprising high density material. For the potassium peak (1.46 MeV) we again use a mass attenuation coefficient of $0.0528 \mathrm{~cm}^{2} / \mathrm{g}$ noting also that a value of $0.0522 \mathrm{~cm}^{2} / g$ is given for a granite by $L \varnothing v b e r g(1984)$. Using the former value and a bulk density of $2.7 \mathrm{~g} / \mathrm{cm}^{3}$ (e.g. a limestone), we obtain the attenuation curve shown by the dashed line in Figure 1a with porosity and water saturation both set at $20 \%$. Here the $90 \%$ attenuation threshold is obtained at a very shallow depth of $20 \mathrm{~cm}$ due to the higher density. Finally we show the reference attenuation curve for water (fresh water with a density of $1 \mathrm{~g} / \mathrm{cm}^{3}$ ) which indicates the extent to which the thickness of the water column will attenuate gamma ray flux. 
The type curves shown in Figure 1a illustrate the attenuation behaviour of a uniformly radioactive half-space and indicate the degree to which any variations in the vertical extent of near-surface materials may modify the attenuation behaviour.

\subsection{Degree of saturation}

In order to further investigate the behaviour of water content (degree of saturation) on radiometric attenuation in soils we use the formulations discussed by Løvberg (1984) and Grasty (1997). As noted previously, since water has 1.11 times as many electrons by weight compared to most dry soils and rocks, water is 1.11 times more effective in attenuating gamma radiation than a typical dry material. The relationship between the linear attenuation coefficient of a wet soil $\left(\mu_{w}\right)$ and a dry soil $\left(\mu_{d}\right)$ is given by:

$\mu_{\mathrm{w}}=\mu_{\mathrm{d}}(1+1.11 \mathrm{w})$

where soil moisture (w) is defined as the weight of water in $1 \mathrm{~g}$ of dry soil (Løvberg, 1984).

The variation of the soil surface count rates with soil moisture for a uniform radioactive material is then given by:

$\mathrm{N}_{1}=\mathrm{N}_{2}\left(1+1.11 \mathrm{w}_{2}\right) /\left(1+1.11 \mathrm{w}_{1}\right)$

where $N_{1}$ and $N_{2}$ are the count rates at two different soil moistures $w_{1}$ and $w_{2}$, respectively.

As noted by Grasty (1997), the soil moisture (w) can be replaced by an expression involving porosity, degree of saturation and dry density. Noting the previous volumetric definition of degree of saturation (S), equation (5), we find the volume of water $\left(V_{w}\right)$ can be defined by:

$\mathrm{V}_{\mathrm{w}}=\mathrm{S}$ e $\mathrm{V}_{\mathrm{s}}$

where e is known as the void ratio and may be written in terms of porosity $(\varnothing)$ as:

$\mathrm{e}=\mathrm{V}_{\mathrm{v}} / \mathrm{V}_{\mathrm{s}}=\varnothing /(1-\varnothing)$

Setting $V_{s}=1$, in equation (11) for a unit mass of solid, we obtain the required mass soil moisture content as:

$w=V_{w} / \rho$

where $\rho$ is the dry bulk density. Equations (11), (12) and (13) are then used to rewrite equation (10) to obtain the change in count rates in the same soil (of given density and porosity) due to a change in water saturation (S).

As previously, we consider soil porosities in the range from $40 \%$ to $80 \%$ to provide an assessment of the attenuation with degree of saturation in the context of a uniform (i.e. thick) material. Figure $1 \mathrm{~b}$ shows the attenuation behaviour of two reference mineral soils having bulk densities of 1.1 and 1.6 $\mathrm{g} / \mathrm{cm}^{3}$ to a full range of saturation conditions. At full saturation, attenuation is in the range 30 to $40 \%$ and a quasi-linear decay behaviour is observed. There is a significant dependence on the behaviour observed with the degree of porosity. If we take the lower density $\left(1.1 \mathrm{~g} / \mathrm{cm}^{3}\right)$ mineral soil and 
increase the porosity to $60 \%$, a much greater sensitivity to water saturation is observed (the LOW DENSITY, HIGH POROSITY curve in Fig. 1b).

A further curve for a higher porosity mineral soil (e.g. a clay with $50 \%$ porosity) with a bulk density of $1.2 \mathrm{~g} / \mathrm{cm}^{3}$ again shows a rapid attenuation and the reduction in count rate approaches $50 \%$ at full saturation. The three curves serve to emphasise the strong dependence of radiometric attenuation characteristics on the near-surface porosity of mineral soils. Following the previous analysis we next consider an organic soil with a bulk density of $0.1 \mathrm{~g} / \mathrm{cm}^{3}$ and a porosity of $80 \%$ (as previously). The sensitivity of the attenuation curve is quite distinct with a reduction in count rate of $80 \%$ at a water saturation of only $10 \%$. The behaviour of an intact bedrock material with bulk density of $2.7 \mathrm{~g} / \mathrm{cm}^{3}$ (e.g. a limestone) with a porosity of $10 \%$ is shown; the curve displays the lowest sensitivity to degree of saturation. Finally in order to demonstrate the behaviour of weathered/fractured (i.e. dual porosity) at-surface bedrock, the behaviour of the same material with a porosity $60 \%$ is also shown. The attenuation curve in this case displays a slightly more rapid decay than that of the high density mineral soil.

The type behaviour of soils (and bedrock) summarised in Figure 1 is intended to provide a framework for the assessment of radiometric attenuation in different types of soils. It is anticipated that soil mixtures such as organo-mineral soils will display intermediate behaviour. Figure $1 \mathrm{a}$ is used to demonstrate the principal thickness of the material contributing to the soil surface gamma ray flux. Using a 90\% contribution rule, the thicknesses range from $20 \mathrm{~cm}$ (limestone) to $60 \mathrm{~cm}$ (wet peat). In the unusual case of dry peat, the principal thickness may extend to several metres. Wet peat, when less than $60 \mathrm{~cm}$ thick, may begin to show significantly different (larger) fluxes than thicker zones. The same is true for the other non-organic materials but the behaviour would be confined to smaller thickness (e.g. $<40 \mathrm{~cm}$ ) as indicated in Figure 1 a.

Given sufficiently thick materials, the attenuation of gamma rays in response to the degree of saturation would be as shown in Figure $1 \mathrm{~b}$. Mineral soils, with low porosity, would potentially display quite limited attenuation characteristics while any higher porosity materials (clays, weathered bedrock) would provide $>40 \%$ attenuation towards higher (>70\%) saturation levels. The clear outliers in behaviour are the high porosity, low density organic soils. The attenuation response is non-linear and appears highly sensitive to the amount of water in the interval from zero to $20 \%$ saturation. Beyond this interval (say $>40 \%$ saturation) the organic soils would display essentially the same flux at all saturations. In comparative terms, the organic soils appear to be distinguishable by their gamma ray attenuation characteristics.

\section{Methodology}

\subsection{Airborne radiometric data}

The Tellus airborne geophysical survey was conducted over a two year period (2005 and 2006) and covered the geopolitical landmass of Northern Ireland, an area of $14,160 \mathrm{~km}^{2}$. Flight lines were extended about $2 \mathrm{~km}$, both over the coast and into the Republic of Ireland. The lines were spaced at intervals of $200 \mathrm{~m}$ and orientated at $345^{\circ}$ relative to true north, on the basis of geological trends. The nominal flight height was $56 \mathrm{~m}$, rising to $200 \mathrm{~m}$ over populated areas. The western portion of the survey took place between 01 July and 05 October 2005 and the eastern survey took place 
between 29 March and 31 May 2006. An examination of meteorological data indicates that the soil moisture regime over the period of the surveys was representative of its long term variation.

Radiometric data were acquired with an Exploranium GR820 256 channel gamma spectrometer system comprising 32 litres of downward-looking Nal(TI) detectors and 8 litres of upward-looking detectors. Full spectrum sampling took place at $1 \mathrm{~s}$ intervals which equates to a distance of $\sim 60 \mathrm{~m}$ along each flight line. Standard procedures for the calibration and processing of the airborne data as described in AGSO publications (Minty et al., 1997) and IAEA (IAEA, 1991) were carried out. Full details of the data processing, levelling and seasonal corrections applied to the data set are given by Beamish et al. (2006).

Uranium $\left({ }^{238} \mathrm{U}\right)$ is measured through the radon daughter ${ }^{214} \mathrm{~B}$ in its decay chain, while thorium $\left({ }^{232} \mathrm{Th}\right)$ is measured through ${ }^{208} \mathrm{Tl}$ in its decay chain. Potassium $\left({ }^{40} \mathrm{~K}\right)$ is measured directly at $\left.1461 \mathrm{keV}\right)$. It is conventional to assume secular equilibrium in the decay chains of ${ }^{238} \mathrm{U}$ and ${ }^{232} \mathrm{Th}$ and report the results as equivalent uranium (eU) and equivalent thorium (eTh). The standard energy windows used are shown in Table 1.

Table 1. Spectral energy ranges of the airborne radiometric data.

\begin{tabular}{|l|l|l|}
\hline Window & Nuclide & Energy range (MeV) \\
\hline Thorium (Th) & ${ }^{208} \mathrm{Tl}(2.61 \mathrm{Mev})$ & $2.41-2.81$ \\
\hline Uranium (U) & ${ }^{214} \mathrm{Bi}(1.76 \mathrm{Mev})$ & $1.66-1.86$ \\
\hline Potassium (K) & ${ }^{40} \mathrm{~K}(1.46 \mathrm{MeV})$ & $1.37-1.57$ \\
\hline Total & -------------- & $0.41-2.81$ \\
\hline
\end{tabular}

The radiometric data considered here have previously been presented and discussed largely in terms of individual radio elements. Jones and Scheib (2007) consider the full data set and describe the ground calibration of the airborne data using soil samples and laboratory gamma spectrometry.

The use of low altitude gamma ray data to provide spatial discrimination of soils and rocks has a considerable history (e.g. Schwarzer and Adams, 1973). Most existing studies have investigated airborne radiometric data and soil/bedrock associations using the thorium, uranium and potassium estimates together with their ratios (Schwarzer and Adams, 1973; Bierworth, 1997). The issue of attenuation due to soil moisture is noted but usually treated at the cautionary level in terms of data interpretation (e.g. Bierworth and Brodie, 2005). While it is stressed that the individual radionuclides and their ratios do offer the most appropriate means of classifying materials, the Total Count (TC) data, covering a wider spectral range, offer a higher signal/noise ratio than the individual components. Thus when studying attenuation and examining the low count behaviour of the data, the signal/noise ratio is of paramount importance.

The Tellus radiometric data provide two measures of Total Count information both discussed in IAEA (2003). The first measure is the Total Count (in cps) across the energy range from 0.41 to $2.81 \mathrm{MeV}$ (Table 1) and this includes contributions from both natural and artificial sources. The second 
measure is the Total Count expressed as an air absorbed dose rate (in $\mathrm{nGy} / \mathrm{h}$ ). For this data set, a linear relationship exists and the two were found to be related by $T_{d}=1.0+0.024 * T C$ where $T_{d}$ is in $\mathrm{nGy} / \mathrm{h}$ and TC is in cps. For the purposes of this study, the TC data in cps are used.

The ground area or footprint, which contributes most radioactivity to each $1 \mathrm{~s}$ measurement, was assessed by Pitkin and Duval (1980) and the modelling methods used in the calculation are discussed by Billings and Hovgaard (1999). For a stationary measurement, at a height of $60 \mathrm{~m}, 90 \%$ of the airborne response will be provided across a circle of radius 160 to $180 \mathrm{~m}$ (Kock and Samuelsson, 2011). In practice, for a moving measurement, the footprint will be elliptical and the $90 \%$ contribution area would cover 109,000 $\mathrm{m}^{2}$ (Billings and Hovgaard, 1999). Within that ellipse, the greatest contribution will come from directly beneath the aircraft and will fall off rapidly with lateral distance from the flight line.

This preliminary study uses soil and bedrock (e.g. soil parent material) information at a scale of $1: 250,000$ to obtain initial, overview information on the behaviour of radiometric attenuation characteristics. Spatial classification of the radiometric data was undertaken using ArcGIS ${ }^{\mathrm{TM}}$ software (Environmental Systems Research Institute, Inc., ESRI). The Tellus radiometric data, restricted to elevations $<180 \mathrm{~m}$, comprise a total of 1,337,703 data points including offshore data. When confined to the onshore area, the data set reduces to $1,315,605$ data points while still sampling the inland water bodies. In the statistical studies that follow, the data from these areas are excluded. Given that the airborne survey data were uniformly sampled across NI, the number of data points obtained for each soil/bedrock classification is recorded as a proxy for the relative areal extent of the sampling.

\subsection{The soils of $\mathrm{NI}$}

A useful and detailed guide to the soils of Ireland is provided by Gardiner and Radford (1980). In the case of Northern Ireland, the soil mapping database of the Department of Agricultural and Rural Development (DARD) was generated between 1987 and 1997 (Jordan et al., 2000) for the purposes of agricultural research. Seventeen 1:50,000 map sheets and a single 1:250,000 map were published (Cruikshank, 1997). The majority of NI soils comprise peats and rankers ( $24 \%$ of the total), poorly drained gley soils (54\%) and freely drained soils (16\%). In more recent years attention has turned to the measurement and estimation of soil carbon stocks (e.g. Tomlinson and Milne, 2006; Kiely et al., 2010). The 1:250,000 DARD database identifies 16 categories of soil types as shown in Table 2.

Table 2. The DARD classification of the soils of Northern Ireland by soil profile code and description. Nsamp refers to the number of radiometric samples (from a total of 1,115,734). Nbed is the number of bedrock units (from a total of 11) underlying each soil. The two major bedrock types and their percentages are also listed.

\begin{tabular}{|l|l|l|l|l|}
\hline Soil Profile & Description & Nsamp & Nbed & Bed major type and \% of total \\
\hline ALL & Alluvium & 33,317 & 10 & BASA (28\%), SAND (21\%) \\
\hline BE & Brown Earth & 123,007 & 11 & BASA (37\%), LITH (19\%) \\
\hline BP & Brown Podzol & 30,100 & 11 & GRAN (37\%), LITH (22\%) \\
\hline DIST & Disturbed & 5,184 & 5 & MUDS (18\%), BASA (11\%) \\
\hline G & Mineral Gley & 554,554 & 11 & BASA (27\%), LITH (18\%) \\
\hline G+BE & Mineral Gley + Brown Earth & 26,825 & 4 & LITH (97\%), MUDS (1\%) \\
\hline
\end{tabular}

Page 11 of 37 


\begin{tabular}{|l|l|l|l|l|}
\hline G+OA & Mineral Gley + Organic & 1,318 & 1 & LITH (100\%) \\
\hline G+R & Mineral Gley + Ranker & 17,858 & 4 & LITH (97\%), MUDS (0.5\%) \\
\hline HG & Groundwater Humic Gley & 55,235 & 11 & PSAM (30\%), BASA (29\%) \\
\hline HR & Humic Ranker (<40 cm) & 36,859 & 10 & BASA (23\%), PSAM (19\%) \\
\hline OA & Organic Alluvium & 2,605 & 6 & MUDS (36\%), BASA (22\%) \\
\hline POD & Podzol & 17,689 & 10 & PSAM (41\%), GRAN (20\%) \\
\hline PT & Peat & 147,145 & 11 & PSAM (32\%), BASA (25\%) \\
\hline R & Ranker & 38,796 & 10 & LITH (29\%), BASA (21\%) \\
\hline SR & Sand Ranker & 3,144 & 6 & MUDS (51\%), LITH (37\%) \\
\hline URB & Urban & 22,098 & 10 & LITH (29\%), BASA (27\%) \\
\hline
\end{tabular}

Descriptions of the soil series are given by Gardiner and Radford (1980) and Cruikshank (1997). Table 2 identifies several types of gley soil ( $G, G+B E, G+O A, G+R$ and $H G)$ in which drainage is impeded. The soils develop under the influence of permanent or intermittent waterlogging. The causes of drainage impedance vary and include groundwater influences (e.g. groundwater humic gley, HG). Four classes of humic or organic soils are identified as HG, HR, PT and OA. Peats, the major organic series, are characterised by a high content of organic matter (over $30 \%$ ) and by being at least $30 \mathrm{~cm}$ in depth. Two basically different types, blanket and basin peat, occur. Water saturation in virgin peat systems may be very high (typically $>90 \%$ by volume).

The podzol soils are characterised by depleted nutrients and are acidic. The brown earths are a mature and well-drained soil. All shallow or thin soils (generally $<30 \mathrm{~cm}$ ) are identified with the generic term 'ranker'. Three of the soil classes (ALL, OA and PT) are also classes identified in the superficial geological data base (see later).

The soil classification database excludes all water bodies and provides a radiometric sampling total of 1,115,734 data points. Three of the classifications (DIST, OA and URB) are excluded from further analysis as they are more appropriate for detailed studies. The main analysis thus takes place using the remaining 13 unit soil series classification. As indicated in Table 2 by the data sampling (Nsamp), the 5 largest soil series in the DARD classification are mineral gley $(49.7 \%)$, peat (13.2\%), brown earth (11\%), groundwater humic gley $(4.9 \%)$ and ranker (3.5\%). The spatial distribution of the13 units, together with urban soils, is shown in simplified form in Figure $2 a$.

The DARD data base includes a soil parent material (bedrock) classification except in the case of the ALL (alluvium), DIST (disturbed), OA (organic alluvium), PT (peat) and URB (urban) classes. In order to overcome the limitations of the existing parent material classification, additional geological databases were examined in relation to providing an assessment of parent material for the DARD soil data base.

\subsection{Superficial deposits}

In addition to the bedrock classification for NI discussed later, a superficial (Quaternary) database was examined in relation to the radiometric data. The 1:250,000 geological superficial classification for NI $(v 2.18,2009)$ provided by the Geological Survey of Northern Ireland (GSNI) provides a 12 unit classification of superficial cover rocks. Glacial sediments (diamicton, or till) dominate the landscape 
and account for $66 \%$ of the total superficial cover. The second two most extensive units in the database are peat (with 15\%) and alluvium (with $8 \%$ ). These latter two units are also included in the soils classification and so an analysis of radiometric data using a superficial classification does not provide much additional information. The main analysis conducted here uses the bedrock classification described below.

\subsection{Bedrock}

The bedrock database is a recent 1:250,000 geological bedrock classification for $\mathrm{NI}(\mathrm{v} 2.18,2009)$ provided by the GSNI. The database provides a 151 unit classification of bedrock geology when using full rock lexicon code descriptions. When a simpler lithological classification is used the number of unit descriptions reduces to 57. For practical purposes, these classifications have been further simplified. The database derived from the 1:250,000 mapping, is referred to as the simplified bedrock database. The simplified lithological classification was developed primarily for geochemical analysis (Smyth, 2007) and comprises just 11 lithological (ROCK) classifications. The simplified classifications are listed in Table 3 along with the rock type descriptions from the lexicon.

Table 3 The simplified bedrock classification of Northern Ireland. Nsamp refers to the number of radiometric samples (from a total of $1,163,457$ ). The two major soil types and their percentages, associated with each bedrock unit are also listed.

\begin{tabular}{|c|c|c|c|c|}
\hline CODE & BEDROCK & ROCK TYPE CONSTITUENTS & Nsamp & Major Soils \\
\hline ACID & Acid Volcanics & Gabbro, diorite & 13799 & PT (37\%), G (35\%) \\
\hline ANDE & Andesite & Andesite & 1742 & G (76\%), PT (15\%) \\
\hline BASA & Basalt & $\begin{array}{l}\text { Basalt, metamorphosed basaltic rock, } \\
\text { metamorphosed lava \& tuff, } \\
\text { interbasaltic bauxitic clay, dolerite }\end{array}$ & 285194 & G (52\%), BE (16\%) \\
\hline CONG & Conglomerate & All conglomerates and psephite & 30586 & G (48\%), PT (14\%) \\
\hline GABB & Gabbro & Gabbro, diorite & 8599 & $\begin{array}{l}\text { G (33\%), POD } \\
(21 \%)\end{array}$ \\
\hline GRAN & Granite & $\begin{array}{l}\text { Granite, granodiorite, felsite, granite } \\
\text { dykes, granophyre, quartz feldspar } \\
\text { porphyry, tonalite }\end{array}$ & 50705 & G (26\%), BP (22\%) \\
\hline LIME & Limestone & $\begin{array}{l}\text { Limestone, argillaceous limestone, } \\
\text { limestone \& argillaceous rocks } \\
\text { interbedded, mudmound reef } \\
\text { limestone, limestone \& mudstone } \\
\text { interbedded, chalk \& sandstone, } \\
\text { dolomitic limestone }\end{array}$ & 104338 & G (54\%), PT (8\%) \\
\hline LITH & Lithic Arenite & $\begin{array}{l}\text { Lithic arenites of the Southern } \\
\text { Uplands-Down-Longford Terrane } \\
\text { (greywackes) }\end{array}$ & 214812 & $\begin{array}{l}\text { G (46\%), G+BE } \\
(12 \%)\end{array}$ \\
\hline MUD & Mudstone & $\begin{array}{l}\text { All mudstone units, argillaceous } \\
\text { layers, silty mudstone }\end{array}$ & 135335 & G (60\%), PT (12\%) \\
\hline PSAM & Psammite + Semipelite & $\begin{array}{l}\text { All psammite layers, } \\
\text { Qulleter } \\
\text { Quartzite, metamorphosed lava \& } \\
\text { tuff (Dalradian) }\end{array}$ & 159104 & PT (30\%), G (28\%) \\
\hline SAND & Sandstone & All sandstone units, breccia and & 159243 & G (54\%), PT (14\%) \\
\hline
\end{tabular}


As indicated in Table 3 by the data sampling (Nsamp), the five largest bedrock series in the simplified bedrock classification are basalt (24\%), lithic arenite (18\%), sandstone (14\%), psammite (14\%) and mudstone (12\%). The spatial distribution of the 11 bedrock units is shown in Figure $2 \mathrm{~b}$. It is worth noting, in the general UK context, that the occurrence of the Antrim Flood Basalts occupying a major portion of NI (Fig. 2b) is largely specific to Northern Ireland and a portion of western Scotland defining the North Atlantic Igneous Province (Mitchell, 2004).

Table 2 also makes use of the simplified 11 unit bedrock classification scheme of Table 3 to list the number of bedrock units (Nbed) associated with each soil unit. The major bedrock type associated with each soil unit (Bed major type) together with the percentage of the total (Nsamp) associated with each of the two major bedrock units are also provided. Most of the soils have spatial associations with the majority of bedrock types with the exception of the mineral gley mixtures and sand rankers. The former group of soils is largely associated with the litho arenite bedrock and basalt. The majority of sand ranker soils are associated with mudstone bedrock. Additional information of bedrock/soil associations can be obtained from Tables 2 and 3 . The soil/bedrock associations are primarily dominated by the large size and distribution of the two main soil groups ( $G$ and PT).

\section{Results}

The analyses are conducted using Total Count (TC) data. In order to provide an estimate of the variance of these data, data across the large central body of water (Lough Neagh, Figure 2a) were used to examine the statistics of a theoretically null radiometric response. Lough Neagh, with an area of $392 \mathrm{~km}^{2}$, is the largest lake in the British Isles. Although it has an average depth of about $9 \mathrm{~m}$ the Lough is very shallow around the margins. In order to exclude potentially shallow water, a subarea that excluded locations within $500 \mathrm{~m}$ of the margins was selected. The sub-area provided 27,890 samples of TC data. The standard deviation of these data was $41 \mathrm{cps}$ and this then provides a reference noise estimate for the analyses described below.

\subsection{Soils}

The soil classified radiometric data (Table 2) have been examined statistically. Due to the size and extent of the spatial distributions considered (Fig. 2a), each soil classification inevitably samples a wide range of bedrock types as noted in Tables 2 and 3.

The four histograms shown in Figure 3 summarise the type of behaviour displayed by the Total Count data across all the data (Fig. 3a) and then the 3 major soil types. The histograms all have equal numbers of bins (100) and bin sizes of $50 \mathrm{cps}$. The distribution obtained for all the data (Fig. 3a) exhibits a multi-modal continuum of responses, as expected. A major contribution is observed across the interval 1500 to $2000 \mathrm{cps}$. The frequency distribution attenuates rapidly above $2500 \mathrm{cps}$ leaving a long tail of high values defining the most radiogenic responses at values exceeding 3000 cps. The distribution obtained for freely draining brown earth (BE) soils is shown in Figure $3 \mathrm{~b}$ and exhibits very well-defined bi-modal behaviour with an additional higher value shoulder centred on a value of $2500 \mathrm{cps}$. The lower value mode displays a very highly peaked distribution at values $<750$ cps and it is instructive to examine the bedrock classifications at these low values. The number of data samples obtained for $\mathrm{TC}<750 \mathrm{cps}$ is 34,246 . The major bedrock contribution, for this subset, is obtained over basalt ( $N=32,725$ or $95 \%$ of the subset), the second largest bedrock contribution then 
comes from limestone ( $\mathrm{N}=628$ or $2 \%$ of the subset). It is evident that the basalt bedrock formation is a significant contributor to the low value behaviour.

The large sample TC distribution for mineral gley soils is shown in Figure 3c. The distribution is again at least bi-modal. The major peak occurs in the vicinity of $1750 \mathrm{cps}$ with a relatively broad low value peak in the vicinity of $750 \mathrm{cps}$. The major bedrock contribution, for the subset with $\mathrm{TC}<750 \mathrm{cps}$, is again obtained over basalt ( $N=69,408$ or $81 \%$ of the subset). The distribution of TC values for peat (Fig. 3d) is remarkably skewed to very low values (note the increased scale of relative frequency). The main peak in the distribution occurs between 150 and $250 \mathrm{cps}$ and accounts for $25 \%$ of the total distribution. The major bedrock contributions, for the subset with $\mathrm{TC}<500 \mathrm{cps}$, are obtained over basalt ( $33 \%$ of the subset) and psammite ( $32 \%$ of the subset). The highly skewed and low value distribution obtained for peat appears to be intrinsic to this soil type, rather than derived from a bedrock (e.g. basalt) association.

The distributions of the other main soil types are summarised in Figure 4. Figure 4a shows the 3 mineral gley mixed soils of the DARD classification; none exhibits the low value (TC $<750 \mathrm{cps}$ ) peak identified in the individual mineral gley distribution (Fig. 3c). The distributions obtained for the G+BE and $\mathrm{G}+\mathrm{R}$ (not shown) pair are similar while the $\mathrm{G}+\mathrm{OA}$ is characterised by a slightly lower peak value presumably associated with the organic component. The two humic soils ( $H G$ and HR) display distributions that closely resemble the highly skewed, low value distribution obtained for PT (Fig. $3 d)$. The HR distribution additionally displays an extensive tail towards higher values.

The two freely draining podsolised soil distributions (Figure 4c) show distinctly different characteristics. Brown podzol soils, associated with an absence of peat and gley in the top $50 \mathrm{~cm}$, display a bi-modal distribution. The POD distribution contains high and low ( $\mathrm{TC}<750 \mathrm{cps}$ ) value peaks together with a shoulder peak in the vicinity of $2500 \mathrm{cps}$.

Rankers are formally classified as non-calcareous soils over non-calcareous rock or massive limestone. Sand rankers are soils formed in non-calcareous, unconsolidated sandy deposits other than alluvium. The two ranker distributions, shown in Fig. $4 \mathrm{~d}$, both display a similar higher value peak in the vicinity of $2700 \mathrm{cps}$. The sand ranker distribution shows a lower value ( $1000 \mathrm{cps}$ ) high peak that is distinct from the lower value $(\sim 500 \mathrm{cps})$ observed in the ranker distribution.

Of the distributions discussed above only the three mixed gley soils ( $G+B E, G+O A$ and $G+R$ ) and the brown podzol soil display an apparent absence of low value enhancements in the observed distributions. As can seen in Table 1 the bedrock associations of the three mixed gley soils are largely limited to one unit (LITH) while the brown podzol soil is distributed across all bedrock types but largely associated with the GRAN and LITH units. It is clearly also necessary to examine the TC behaviour of the bedrock units in conjunction with the soil information and this is now considered.

\subsection{Bedrock}

Ideally, we would wish to examine the radiogenic properties of the bedrock parent material in the absence of soil material effects, such as attenuation. A simple first-pass screening of the data is suggested by the analysis of the soil classified behaviour discussed above. It was demonstrated that the TC humic soil (PT, HG and HR) distributions showed highly skewed behaviour to low values with single peaks observed at $\mathrm{TC}<500 \mathrm{cps}$. A statistical appraisal was therefore carried out first using the TC data classified by bedrock and secondly by then omitting the data associated with the 3 humic soil classes. Four bedrock classified examples from the analysis are shown in Figure 5. A logarithmic abscissa is used to emphasise the low count behaviour. 
The ACID bedrock class (Fig. 5a) is originally a double peaked distribution which then reduces to more unimodal behaviour in the absence of humic soil cover. This same behaviour is repeated in the majority of TC bedrock distributions to a greater or lesser extent, as indicated in Figure 5 . The original low value distribution for basalt (Fig. 5b) is simplified to apparent unimodal behaviour but still maintains central moments largely below $1000 \mathrm{cps}$. Of the 11 bedrock classifications considered, only 3 display minor change in the distributions when the humic soil classes are omitted. The 3 bedrock units displaying this behaviour are ANDE (a bimodal distribution), GRAN (unimodal) and LITH (unimodal).

The first-pass analysis of bedrock TC behaviour in the absence of the significant attenuation effects of humic soils appears to provide an improved assessment of the radiogenic properties of the bedrock classes. The analysis undertaken omitting the humic soil classes is now used to summarise the general behaviour of the bedrock classified TC data. It will be appreciated that a number of the TC frequency distributions presented above (both soils and bedrock classified) are multi-modal, skewed and highly peaked. Such distributions do not permit simple parametric (e.g. normal or lognormal) assessments of the central modes and variance of the data. This is a common situation when dealing with large scale regional data sets (Reimann \& Filzmoser, 2000).

\subsection{Summary statistics}

While acknowledging the above caveat, the distributions of the bedrock classified TC data (omitting data associated with humic soils) are summarised in the box-whisker plot shown in Figure 6. A logarithmic scale is used since the data span over 2 orders of magnitude and the axis has been terminated at a value of $100 \mathrm{cps}$ to exclude the extensive low value tails of most of the distributions. The interquartile range provides an indication of the central moments of the bedrock responses. Using Figure 5 it is possible to define 3 categories of central moments which comprise 1) TC $<1000$ cps (BASA), 2) $1000<T C<2000$ cps (ACID, ANDE, CONG, GABB, LIME, MUDS, PSAM and SAND) and 3) TC $>2000 \mathrm{cps}$ (GRAN and LITH). While the central moments summarise average properties it is acknowledged that it is the departures from the averages (the tails) that are of interest in more detailed studies.

Having obtained an assessment of characteristics using a conditioned bedrock classification, it is now possible to return to the soil classified data and consider refinements to their assessment. The boxwhisker plot summarising the TC distributions according to soil classification is shown in Figure 7. The data range (100 to $10,000 \mathrm{cps})$ is the same as that used in the corresponding bedrock assessment. The box whisker soil plot summarises the full distributions (histograms) of the individual soils shown previously (Figures 3 and 4 ) and it should again be noted that none conform to standard parametric behaviour. Using Figure 7 it is possible to define 3 categories of central moments which comprise: TC predominantly $<2000 \mathrm{cps}$ (the humic soils HG, HR and PT), $750<T C<2000 \mathrm{cps}$ (ALL, BE, $G, P O D, R$ and $S R$ ) and TC predominantly $>2000 \mathrm{cps}$ (BP, and the gley soils $\mathrm{G}+\mathrm{BE}, \mathrm{G}+\mathrm{OA}$ and $\mathrm{G}+\mathrm{R}$ ). The latter distributions also appear to be associated with less dispersive behaviour.

The major components of the bedrock sampling, and hence parent material, involved in the soil classification are summarised in Table 2. It can be noted that 7 of the main 13 soil units are associated with basalt as the primary or secondary parent material. Since basalt is a relative low value TC outlier in the bedrock assessment (Fig. 6), the soil classification TC analysis was repeated 
with the exclusion of soil locations with bedrock basalt associations. The central moment boxes (i.e. the first and third quartiles) of this analysis are overlain as larger, outer boxes on the previous results in Figure 6. Although a function of the number and extent of the bedrock associations, it might be expected that the TC central moments would remain the same or move to higher values. The former behaviour is observed in the soils BP, the 3 gley soil mixtures, POD and SR while the latter behaviour is observed for the soils ALL, BE, G and R. The three organic soils HG, HR and PT display a consistent movement to higher TC values.

Having established the general statistical behaviour of radiometric TC with soil type and bedrock with special reference to their low value (attenuation) characteristics, it is instructive to examine their behaviour in greater detail. The preceding analysis provides a context in which the low value TC tails of each soil series can be spatially examined. A subset of the TC data for the freely draining brown earth ( $\mathrm{BE}$ ) soils ( $\mathrm{N}=123,007$, Table 2 ) are used as an example. A $48 \times 48 \mathrm{~km}$ area in the $\mathrm{SW}$ of the survey area was selected across an area in which the relative lows (BASA) and highs (GRAN and LITH) of the bedrock response are absent (Fig. 2b). The TC distribution for the total data set is shown in Figure 3b. Due to the non-parametric nature of the distribution it is not possible to employ the usual measures of dispersion (e.g. quartiles). Figure 8 shows the location of the BE soils as polygons and the TC values are provided as posted values for two high/low ranges. The TC data range from 132 to $2666 \mathrm{cps}$ across the selected area. The low range is from 132 to $1000 \mathrm{cps}$ and represents the low value peak in the distribution (Fig. 3b). The upper range is identified by the values exceeding $2000 \mathrm{cps}$. Normally the identification of the high value outliers would be examined in further detail using the individual radioelement values and their ratios.

In Figure 8, the low value BE data across a number of areas form spatially-coherent zones (natural clusters). At the southern margin of the survey (arrowed) a large BE occurrence polygon is entirely characterised by low values. The behaviour observed indicates the integrity of the low value TC data set. Elsewhere, low value clusters are observed within various BE polygons and these are also arrowed. In broad terms the low value zones would be interpreted as areas of highest attenuation and therefore the highest degree of water saturation within the BE soils.

It was anticipated that the freely draining brown earths would not show extensive areas of high attenuation potentially related to increased water saturation and this is generally the case except in specific areas such as that indicated in Figure 8 . The intention here is not to provide a detailed investigation of the variations of attenuation levels of the whole soil series but to indicate the manner in which the soil classified TC data could provide a framework for further, more detailed, studies of soil moisture content within each soil series.

\subsection{Detailed studies of Peat}

The humic soils, particularly peat, have a specific and high sensitivity to soil moisture content and they account for a substantial percentage of the soils of both Northern Ireland and the Irish Republic. In order to further demonstrate the attenuation behaviour of the TC data, two extensive areas of peat were selected for study. In order to accommodate the established influence of bedrock type, the first area considered abuts the coast in the NE (13 $\times 15 \mathrm{~km}$ rectangle, Figure 2$)$ and is underlain by basalt (Fig. 2 b). The second area considered ( $10 \times 7 \mathrm{~km}$ rectangle Figure 2$)$ lies along the political border in the SE of the area and is largely underlain by a sandstone, limestone and 
mudstone Carboniferous bedrock sequence (Fig. 2b). Both study rectangles contain protected Ramsar wetland areas. The first area contains the Garron Plateau Ramsar site and is the largest area of intact blanket bog in Northern Ireland. The peatland complex is described as comprising a series of raised and flushed peat bog units, and a number of oligotrophic water bodies, all within the enveloping blanket bog peat mantle. The second area is the Cuilcagh Mountain Ramsar site which contains the second largest expanse of blanket bog in Northern Ireland. It is contained within a relatively high elevation upland landscape.

The blanket bog peats of Northern Ireland are specifically discussed by EHS (2003). As far as is known, detailed information on both the thickness of peat and its moisture content is not available across the study areas considered. Peat depths, in blanket bog areas are described as very variable, with an average of 0.5 to $3 \mathrm{~m}$ being typical. Where peat has accumulated in depressions, depths in excess of $5 \mathrm{~m}$ are not unusual (EHS, 2003).

Since the underlying bedrock is distinct in the two cases, the distributions of the soil peat series were first obtained for two relevant bedrock classes using the complete data set. The distributions of TC for peats on basalt ( $N=147145)$ and peats not underlain by basalt $(N=110,774)$ are shown in Figure 9 . A logarithmic scale is used to discriminate the low count behaviour and the bin size used is $25 \mathrm{cps}$. It can be noted that both distributions display similar low value central moments. The peat on basalt forms a very highly peaked distribution while the peat not underlain by basalt distribution is far less peaked. The latter also displays greater dispersion to higher count values above $\sim 400 \mathrm{cps}$. The former distribution has a median of $229 \mathrm{cps}$ with first and third quartiles of 172 and $365 \mathrm{cps}$, respectively. The latter distribution has a median of $433 \mathrm{cps}$ with first and third quartiles of 211 and $844 \mathrm{cps}$, respectively. These values form reference levels when considering the peat responses considered below.

\subsubsection{Garron Plateau}

The data across this area were obtained by a series of flights between 27 April and 11 May, 2006. The distribution of soil units across the study area is shown in Figure 10a. The plateau area is dominated by a central NE-SW trending axis of peat that connects to a further extensive area to the $N W$. The elevations range from 0 to $549 \mathrm{~m}$. In the NE a large valley descends to the coast and contains a sequence of rankers, brown earth and alluvial soils. The valley also marks a bedrock transition from basalt to conglomerate (Fig. 2b). The peat area is everywhere underlain by basalt. There is a single large body of water identified at this scale, together with the seawater in the northeast. Provided there is a sufficient vertical column of water (e.g. $>40 \mathrm{~cm}$ for $>90 \%$ attenuation), these bodies should provide a null (theoretically zero) radiometric response. The TC data across the area were gridded at a $50 \mathrm{~m}$ cell size using a natural neighbour algorithm. The resulting image is shown using a continuous linear colour-scale range in Figure 10b. A high value threshold of $700 \mathrm{cps}$ has been used to preserve the dynamic range of the lower values. The maximum value across the grid of values is $2590 \mathrm{cps}$. A few zones of negative values, associated with statistical uncertainty, are observed over the sea. The linework of the soils distribution is also shown for reference. The highest levels of attenuation (e.g. TC $<300 \mathrm{cps}$ ) are clearly observed across the zone of peat over basalt. Outside this zone, TC values increase broadly in association with the trends and spatial variations in soil type. 
The within-peat variability is of interest. In the area towards the NW, significant zones of higher value TC behaviour are observed. According to the simple theory developed previously, such zones could arise due to the presence of drier peat (less water and hence less attenuation) or zones of thinner peat (again less water and hence less attenuation). In order to demonstrate the highest attenuation behaviour, the lowest value zones with $\mathrm{TC}<140 \mathrm{cps}$ are identified in grey. While it is true that these data are undoubtedly approaching the inherent noise level of the data, significant areas of persistent low values are observed including that of the standing water body. It should be noted that many of the remaining, much smaller bodies of standing water (not shown) have dimensions that are likely to be small in relation to the footprint of the airborne measurement. With the exception of a small area in the SE, all the low value TC zones occur within the area of defined peat. The working hypothesis is that given sufficient thickness of peat across both the main Ramsar wetland area and the peat area to the NW, the TC data are able to discriminate near-surface zones of enhanced water content. In addition, where enhanced peat signal levels (e.g. > 365 cps, corresponding to the third quartile, as discussed) are observed in the NW, a thinner peat thickness may be postulated, but reduced water content (drier zones of peat) cannot be ruled out.

\subsubsection{Cuilcagh Mountain}

The data across Cuilcagh Mountain were obtained by a series of flights between 06 and 20 July 2005.The study area rectangle straddles the political border (Fig. 8) and the available data encompass only the northern slopes of the mountain. Since elevation ranges from 70 to $666 \mathrm{~m}$, the information has been assembled on an accurate DTM (Digital Terrain Model) with a $5 \mathrm{~m}$ cell resolution. The images are shown in perspective view looking due south, from the north. The distribution of soil units, draped on the DTM across the study area, is shown in Figure 10c. The area is dominated by the blanket bog of peat that extends upslope towards the mountain ridge. The peat boundary as identified in the DARD soil database is emphasised by a white contour. For this study, a further potential peat boundary, obtained from the CORINE (Coordination of Information on the Environment) land-use $\mathbf{2 0 0 0}$ database for Northern Ireland, is used. Here the land-use code $\mathbf{4 1 2}$ (peat bogs) boundary is identified in black. There are known resolution and interpretation issues when comparing CORINE classifications with other databases on soils (e.g. Cruickshank and Tomlinson, 1996). The two most significant differences between the peat boundaries are identified as $A$ and $B$ in Figure 10c. The first area (A) shows the CORINE peat boundary extending $\sim 1 \mathrm{~km}$ west across the Humic Ranker (HR) soil identified in the DARD database. The second area (B) of the CORINE information defines a large non-peat zone contouring the higher slopes. CORINE peat then continues at higher elevations onto the ridge defined with humic ranker soils in the DARD database. It is also apparent that there are some strong topographic associations with the soil cover particularly in the east where gley soils $(G)$ abut humic ranker (HR) and peat (PT) soils.

The TC data across the area were again gridded using a $50 \mathrm{~m}$ cell size. The resulting image is shown using a discrete linear colour-scale range in Figure 10d. A high value threshold of $700 \mathrm{cps}$ has been used to preserve the dynamic range of the lower values. The maximum value across the grid of values is $3343 \mathrm{cps}$. It is apparent that the dynamic range in this area is more extensive than the corresponding behaviour observed over the basalt (Fig. 10 b). Here the gley soil TC amplitudes exceed $700 \mathrm{cps}$ and provide strong gradients with soil boundaries in the east. Noting that the broad 
peat response is $<300 \mathrm{cps}$, it appears that the low value eastern spur of peat defined in the CORINE map (A, Fig. 10c) matches the observed broad response for peat.

Elsewhere across the main peat area defined in both databases, there are numerous spatially extensive, relative high amplitude responses. These responses exceed the local peat background (e.g. 200 to $300 \mathrm{cps}$ ) by a factor of 2 to 3 . Referring to the sensitivity of the type peat soils to thickness (Fig. 1a) and degree of saturation (Fig.1b), then it is likely that such a response would be associated with the most sensitive attenuation behaviour observed at low values of thickness (e.g. < $50 \mathrm{~cm}$ ) or low values of water saturation (e.g. $<10 \%$ ).

The upper slope area of peat absence identified by the CORINE database (B, Fig. 10c) is indeed associated with increased amplitudes although they occur with considerable lateral zoning. Across the highest slope and ridge, large amplitude responses are observed that show an association with the mountain crest HR soils indentified in the DARD database. At lower elevations, low amplitude TC behaviour is identified in grey/black at values $<100 \mathrm{cps}$ and these zones are predominantly confined to peat classified soils. Typically these zones would be associated with the highest degree of water saturation.

\section{Discussion and Conclusions}

This study has considered the gamma ray attenuation characteristics of soil and bedrock using simple theory and high resolution airborne radiometric data. Existing theory has been re-examined to allow an assessment of soil/bedrock attenuation characteristics in terms of porosity, degree of saturation and dry bulk density. When a given material is considered as a uniformly radioactive halfspace, the attenuation curves indicate the degree to which any vertical changes in the material properties (e.g. soil thickness) may influence the attenuation behaviour observed. Low bulk density organic soils form outliers to the general case in which a $90 \%$ attenuation threshold is observed at depths of $<50 \mathrm{~cm}$. Attenuation (90\%) in peat soils may vary between depths of $60 \mathrm{~cm}$ (when wet) and several metres (when dry). The manner in which the degree of saturation controls the attenuation in soil/bedrock materials has been examined. The sensitivity varies between very low (e.g. low porosity mineral soils) and very high (e.g. high porosity peat). Low porosity mineral soils would typically provide between $30 \%$ and $40 \%$ attenuation when fully saturated while an $80 \%$ porosity peat would provide $90 \%$ attenuation with a water saturation of just $20 \%$. In comparative soil terms, the high organic content soils appear to be distinguishable by their gamma ray attenuation characteristics.

The Total Count radiometric data used in this study comprise over 1 million samples across the soils and bedrock of Northern Ireland. The statistical distributions of the soil classified data display distinct characteristics in their low count behaviour. Extreme highly-skewed distributions (to low counts) are observed in the case of organic soils with the most extreme behaviour observed in the case of peat. The distributions of brown earths, mineral gleys and rankers exhibit multi-modal behaviour with a distinct low count peak.

The statistical distributions of the bedrock classified data reveal a dependence on soil type. When the bedrock classification is repeated with the areas of humic soils omitted, the low amplitude modes of many of the distributions are absent and the central modes of the bedrock response 
appear more peaked (better defined). Knowledge of the attenuation properties of the soils therefore allows an improved assessment of the intrinsic radiogenic properties of the bedrock formations. In the specific case of Northern Ireland, the extensive flood basalt distribution provides a distinctly low value $(<1000 \mathrm{cps}$ ) central response when compared with the majority of bedrock formations (1000 to $2000 \mathrm{cps}$ ). Higher value (2000 to $3000 \mathrm{cps}$ ) central modes are then associated with granites and the lithic arenites (greywackes) of the Southern Uplands-Down-Longford Terrane.

In an analogous manner, it is possible to reclassify the radiometric data in terms of the soil distribution in the absence of underlying basalt. This again leads to an overall improvement in the comparative study of soil radiometric response characteristics. Within this revised soil framework, the low value peat response is quite distinct while the two other organic soils studied here, although displaying low value central moments, provide overlap with a number of other soil responses. Using the freely-draining brown earth soils as an example, the spatial integrity of the low value data set was demonstrated. The low values form spatially-coherent zones (natural clusters) that can potentially be interpreted as areas of increased water content for each soil type.

The degree to which areas covered by peat can be distinguished by the radiometric data was examined in more detail in two studies of extensive blanket bogs. The attenuation levels associated with existing database peat boundaries show broad agreement together with a number of quite distinct differences. Strong intra-peat response variations are also apparent. According to theory, the large response variations observed may be due to variations in thickness and/or water content. It can be postulated that the higher amplitude intra-peat zones may be due to areas with thin peat cover while the areas with the lowest amplitudes coincide with the highest water content. A fuller understanding of the detailed behaviour observed will require appropriate ground investigations to calibrate the radiometric information.

\section{Acknowledgements}

My thanks go to the two referees whose contributions helped improve the manuscript. The data used in the study come from the Tellus Project which was funded by DETI and by the Building Sustainable Prosperity scheme of the Rural Development Programme (Department of Agriculture and Rural Development of Northern Ireland). This paper is published with the permission of the Executive Director, British Geological Survey (NERC).

\section{References}

Appleton, J.D., Miles, J.C.H., Green, B.M.R., Larmour, R., 2008. Pilot study of the application of Tellus airborne radiometric and soil geochemical data for radon mapping. Journal of Environmental Radioactivity 99, 1687-1697. 
Appleton, J.D., Miles, J.C.H., Young., M., 2011. Comparison of Northern Ireland radon maps based on indoor radon measurements and geology with maps derived by predictive modelling of airborne radiometric and ground permeability data. Science of the Total Environment 409, 1572-1583.

Beamish, D., Cuss, R.J., Lahti, M., 2006. The Tellus airborne geophysical survey of northern Ireland: final processing report. British Geological Survey Internal Report, IR/06/136.

Beamish, D., Young. M., 2009. Geophysics of Northern Ireland: the Tellus effect. First Break 27, 4349.

Beamish, D., Farr, G., 2011. Airborne geophysical data used to characterise groundwater dependant wetlands. Near Surface 2011 - 17th European Meeting of Environmental and Engineering Geophysics, Leicester, UK, 12 - 14 September 2011, Extended Abstract.

Beamish, D., White, J.C., 2011. A radiometric airborne geophysical survey of the Isle of Wight, Proceedings of the Geologists' Association, 122, 787-799.

Bierwirth, P.N., 1997. The use of airborne gamma-emission data for detecting soil properties. Proceedings of the Third International Airborne Remote Sensing Conference and Exhibition, Copenhagen, Denmark.

Bierwirth, P.N., Brodie, R.S., 2005, Identifying acid sulfate soil hotspots from airborne gamma radiometric data \& GIS analysis. BRS Report, ISBN 0642475539.

Billings, S., Hovgaard, J., 1999. Modelling detector response in airborne gamma-ray spectrometry. Geophysics 64, 1378-1392.

Bradley, R.I., Milne, R., Bell, J., Lilley, A., Jordan, C., Higgins, A., 2005. A soil carbon and land use database for the United Kingdom. Soil Use and Management 21, 363-369.

Carroll, T.R., 1981. Airborne soil moisture measurement using natural terrestrial gamma radiation. Soil Science 132, 358-366.

Carroll, T.R., 1987. Operational airborne measurements of snow water equivalent and soil moisture using terrestrial gamma radiation in the United States. Large Scale Effects of Seasonal Snow Cover (Proceedings of the Vancouver Symposium, August 1987). IAHS Publ. no. 166.

Cruickshank, M.M., Tomlinson, R.W., 1996. Application of CORINE land cover methodology to the UK - some issues raised from northern Ireland. Global Ecology and Biogeography Letters 5, 235-248.

Cruickshank, J.G., 1997. Soil and environment: Northern Ireland. Agricultural and Environment Science Division, DANI and The Agricultural Environmental Science Department, The Queens University of Belfast, 214pp.

Clymo, R. S., 1992. Models of peat growth. Suo 43, 127-136.

Cook, S. E., Corner, R.J., Groves, P.R. and Grealish, G.J., 1996. Use of airborne gamma-radiometric data for soil mapping. Australian Journal of Soil Research 34, 183-194. 
Davisson, C.M., 1965. Gamma-ray attenuation coefficients. In: Siegbahn (Ed.), Alpha-, Beta- and Gamma-ray Spectroscopy, Vol. 1, North Holland, Amsterdam, pp. 827-843.

Dickson, B.L. and Scott, K.M., 1997. Interpretation of aerial gamma-ray surveys - adding the geochemical factors. AGSO Journal of Australian Geology and Geophysics 17, 187-200.

Endrestol, G., 1980. Principle and method for measurement of snow water equivalent by detection of natural gamma radiation. Hydrogeological Sciences, Bulletin-des Sciences Hydrologiques 25, 7783.

Environment \& Heritage Service (EHS), 2003. Northern Ireland Habitat Action Plan: Blanket Bog, 124.

Gardiner, M.J., Radford, T., 1980. Soil Associations of Ireland and their Land Use Potential: Explanatory Bulletin to Soil Map of Ireland 1980. Soil Survey Bulletin No. 36. An Foras Talúntais, Dublin, Ireland.

Grasty, R.L., 1997. Radon emanation and soil moisture effects on airborne gamma ray measurements. Geophysics 62, 1379-1385.

Grasty, R. L., 1979. Gamma-ray spectrometric methods in uranium exploration, 2, Theory and operational procedures. In: Hood, P.J., (Ed.), Geophysics and Geochemistry in the Search for Metallic Ores, Proceedings of Exploration'77 Symposium, Geological Survey of Canada Economic Geology Report 31, Ottawa, pp. 147-161.

IAEA, 1991. Airborne gamma ray spectrometer surveying. International Atomic Energy Agency, Vienna, Technical Report Series, No. 323.

IAEA, 2003. Guidelines for radioelement mapping using gamma ray spectrometry, International Atomic Energy Agency, Vienna, Technical Report Series, No. 136.

Jones, D.J., Scheib, C., 2007. A preliminary interpretation of Tellus airborne radiometric data. British Geological Survey Commissioned Report, CR/07/061.

Jordan, C., Higgins, A., Hamill, K., Cruickshank, J.G., 2000. The Soil Geochemical Atlas of Northern Ireland. Department of Agriculture and Rural Development, Northern Ireland.

Kechavarzi, C., Dawson, Q., Leeds-Harrison, P.B., 2010. Physical properties of low-lying agricultural peat soils in England. Geoderma 154, 196-202

Kiely, G., McGoff, N., Eaton, J., Leahy, P., Xu, X., Carton, O., 2010. SoilC - Measuring and Modelling of Soil Carbon Stocks and Stock Changes in Irish Soils. EPA report Strive No. 35. EPA, Dublin, Ireland. ISBN: 978-1-84995-320-6.

Kock, P., Samuelsson, C., 2011. Comparison of airborne and terrestrial gamma spectrometry measurements - evaluation of three areas in southern Sweden. Journal of Environmental Radioactivity 102, 605-613. 
Lahti, M., Jones, D.G., 2003. Environmental applications of airborne radiometric surveys. First Break 21, 35-41.

Loijens, H.S., 1980. Determination of soil water content from terrestrial gamma radiation. Water Resources Research 16, 565-573.

Løvborg, L., 1984. The calibration of portable and airborne gamma-ray spectrometers - theory, problems and facilities. Risø Report M-2456, pp. 207.

Minty, B.R.S., 1967. Fundamentals of airborne gamma-ray spectrometry. AGSO Journal of Australian Geology and Geophysics 17, 39-50.

Minty, B.R.S., Luyendyk, A.P.J., Brodie, R.C., 1997. Calibration and data processing for airborne gamma-ray spectrometry. AGSO Journal of Australian Geology and Geophysics 17, 51-62.

Mitchell W.I. (ed.) 2004. The geology of Northern Ireland: Our Natural Foundation. Geological Survey of Northern Ireland, Belfast. ISBN 0852724543.Pires, L.F., Bacchi, O.S., Dias, N.M.P., 2006. Gammaray beam attenuation to assess the influence of soil texture on structure deformation. Nukleonika 51, 125-129.

Pitkin, J. A., Duval, J. S., 1980. Design parameters for aerial gamma ray surveys. Geophysics 45, 1427-1439.

Rawlins, B.G., Webster, R., Lark, R.M., 2007. Understanding airborne radiometric survey signals across part of eastern England. Earth Surface Processes and Landforms 32, 1503-1515.

Rawlins, B.G., Marchant, B.P, Smyth, D., Scheib, C., Lark, R.M., Jordan, C., 2009. Airborne radiometric survey data and a DTM as covariates for regional scale mapping of soil organic carbon across Northern Ireland. European Journal of Soil Science 60, 44-54.

Reimann, C., Filzmoser, P., 2000. Normal and lognormal data distribution in geochemistry: death of a myth. Consequences for the statistical treatment of geochemical and environmental data Environmental Geology 39, 1001-1014.

Schwarzer, T.G., Adams, J.A.S., 1973. Rock and Soil Discrimination by Low Altitude Airborne GammaRay spectrometry in Payne County, Oklahoma. Economic Geology 68, 1297-1312.

Scheib C, Beamish D., 2010. High spatial resolution observations of ${ }^{137} \mathrm{Cs}$ in northern Britain and Ireland from airborne geophysical survey. Journal of Environmental Radioactivity 101, 670-680.

Smyth, D., 2007. Methods used in the Tellus Geochemical Mapping of Northern Ireland. British Geological Survey Open Report, OR/07/022.

Tomlinson, R.W., Milne, R.M., 2006. Soil carbon stocks and land cover in Northern Ireland from 1939 to 2000. Applied Geography 26, 18-39.

Wellock, M., Reidy, B., Laperle, C.M., Bolger, T., Kiely, G., 2011. Soil organic carbon stocks of afforested peatlands in Ireland. Forestry 84, 441-451. 


\section{Figure Captions}

Figure 1. Theoretical attenuation behaviour of soil/bedrock types. The parameters defining the soil types are discussed in the text. (a) Variation with thickness assuming a uniform half-space. A $90 \%$ attenuation level is shown by the horizontal dash line. (b) Variation with degree of saturation (soil moisture or moisture content).

Figure 2. Soil and bedrock maps of Northern Ireland. Three rectangles outline 3 detailed study areas discussed in the text. (a) Soil distribution according to DARD database using a 13-unit (+Urban) soil classification. (b) Simplified 11-unit bedrock classification.

Figure 3. Normalised distributions of the Total Count data for all the data and the 3 major soil types. (a) All data, (b) brown earth (BE), (c) mineral gley (G) and (d) peat (PT). The number of samples (N) is shown for each case.

Figure 4. Normalised distributions of the Total Count data for 8 soil types. (a) mineral gley+brown earth $(\mathrm{G}+\mathrm{BE})$ and mineral gley+organic $(\mathrm{G}+\mathrm{OA})$, (b) groundwater humic gley $(\mathrm{HG})$ and humic ranker (HR), (c) brown podzol (BP) and podzol (POD) and (d) ranker (R) and sand ranker.

Figure 5. Normalised distributions of the Total Count data (logarithmic scale) for the 4 major bedrock classes, with and without humic soil cover. (a) acid volcanic (ACID), (b) basalt (BASA), (c) psammite (PSAM) and (d) sandstone (SAND).

Figure 6. Box and whisker plot summarising the statistical behaviour of the Total Count data (logarithmic scale) classified according to simplified bedrock, and with overlying organic/humic soils omitted. The infilled box indicates the first and third quartiles of each distribution with the enclosed horizontal bar denoting the median value. The terminating bars at the end of each vertical line denote the range of the data. Outliers are omitted. $A C I D=$ acid volcanics, $A N D E=$ andesite,

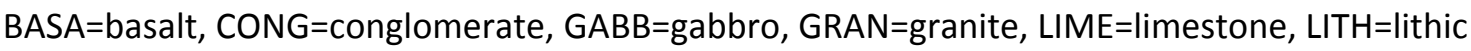
arenite, $M U D=$ mudstone, $P S A M=$ psammite + semipelite, $S A N D=$ sandstone.

Figure 7. Box and whisker plot summarising the statistical behaviour of the Total Count data (logarithmic scale) classified according to soil type. The larger (open) rectangles indicate the central moments (i.e. first and third quartiles) of the distributions when samples with underlying Basalt bedrock are omitted. $A L L=$ alluvium, $B E=$ brown earth, $B P=$ brown podzol, $G=$ mineral gley, 
$\mathrm{G}+\mathrm{BE}=$ mineral gley + brown earth, $\mathrm{G}+\mathrm{OA}=$ mineral gley + organic, $\mathrm{G}+\mathrm{R}=$ mineral gley + ranker, $\mathrm{HG}=$ groundwater humic gley, $\mathrm{POD}=$ podzol, $\mathrm{PT}=$ peat, $\mathrm{R}=$ ranker, $\mathrm{SR}=$ sand ranker.

Figure 8. Brown Earth soil distribution (polygons) in the SW of the survey area within a $48 \times 48 \mathrm{~km}$ rectangle. The southern-most line is the border. The values of the Total Count data are shown using two ranges. The low range is from 132 to $1000 \mathrm{cps}$ and the high range is from 2000 to $2666 \mathrm{cps}$. Areas in which natural clusters of low value counts are observed are highlighted with arrows. Two infill areas indicate (i) the town of Enniskillen and (ii) the Cuilcagh Mountain Ramsar site discussed in the text.

Figure 9. Normalised distributions of the Total Count data (logarithmic scale) for peat on basalt bedrock and peat with no underlying basalt bedrock.

Figure 10. Detailed studies of Total Count data across major blanket bog (Peat) areas. (a) Soil and water distribution across $13 \times 15 \mathrm{~km}$ Garron Plateau area. (b) Total Count (TC) distribution across Garron Plateau area with soil distribution overlaid as lines. The lowest value TC data ( $<140 \mathrm{cps}$ ) are shown in grey. (c) Soil (DARD) distribution across the $10 \times 7 \mathrm{~km}$ Cuilcagh Mountain area. The data are shown overlaid on an accurate DTM looking due South. The heavy white contour line denotes the DARD classified Peat boundary and the heavy black contour denotes the CORINE classified Peat boundary. An area of no Peat within the DARD database is denoted by ' $A$ ' and a no Peat area within the CORINE database is denoted by ' $B$ '. (d) Total Count (TC) distribution across Cuilcagh Mountain area with Peat boundaries identified with white (DARD) and black (CORINE) heavy contours. 

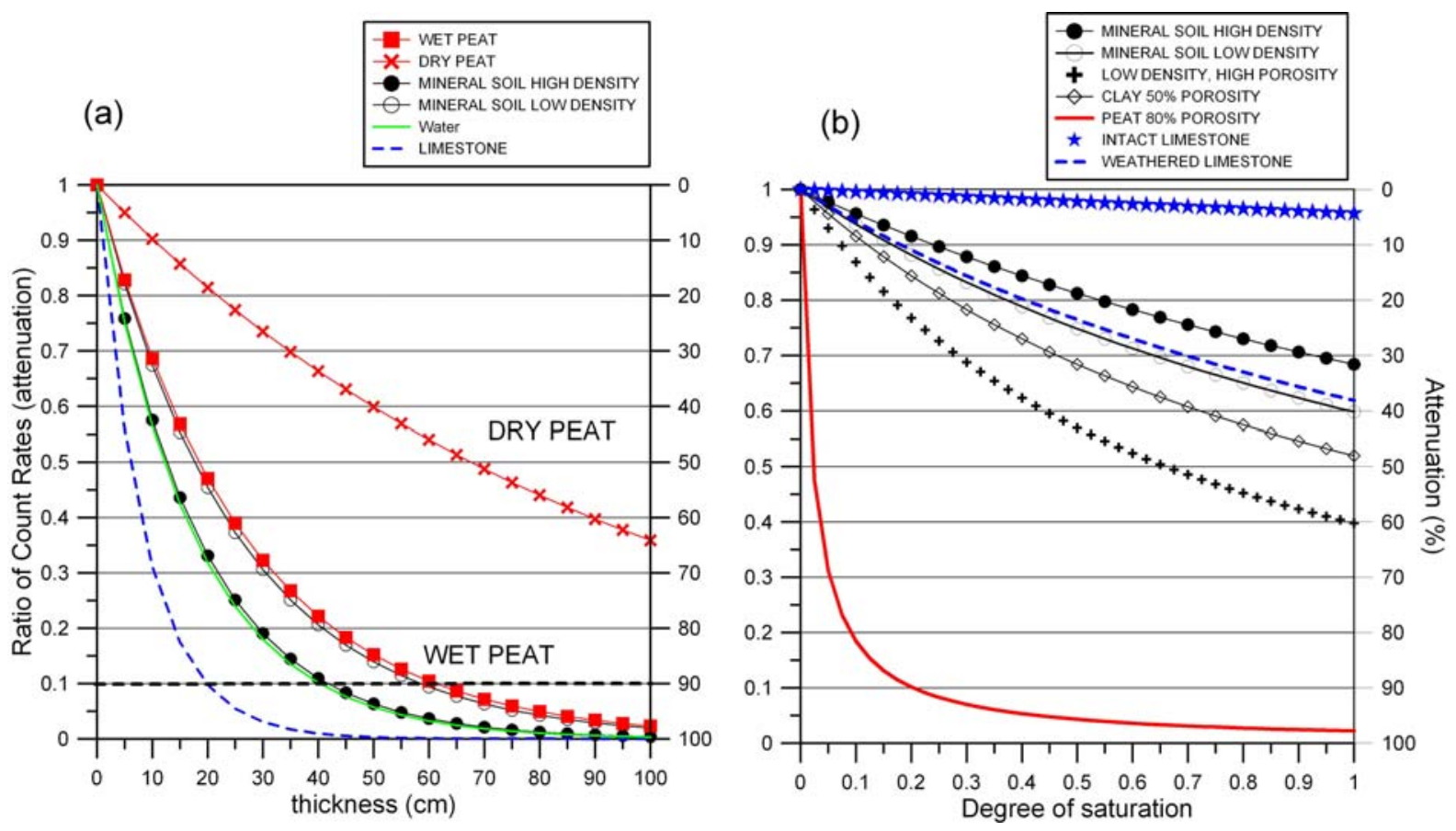

Figure 1 Theoretical attenuation behaviour of soil/bedrock types. The parameters defining the soil types are discussed in the text. (a) Variation with thickness assuming a uniform half-space. A $90 \%$ attenuation level is shown by the horizontal dash line. (b) Variation with degree of saturation (soil moisture or moisture content). 


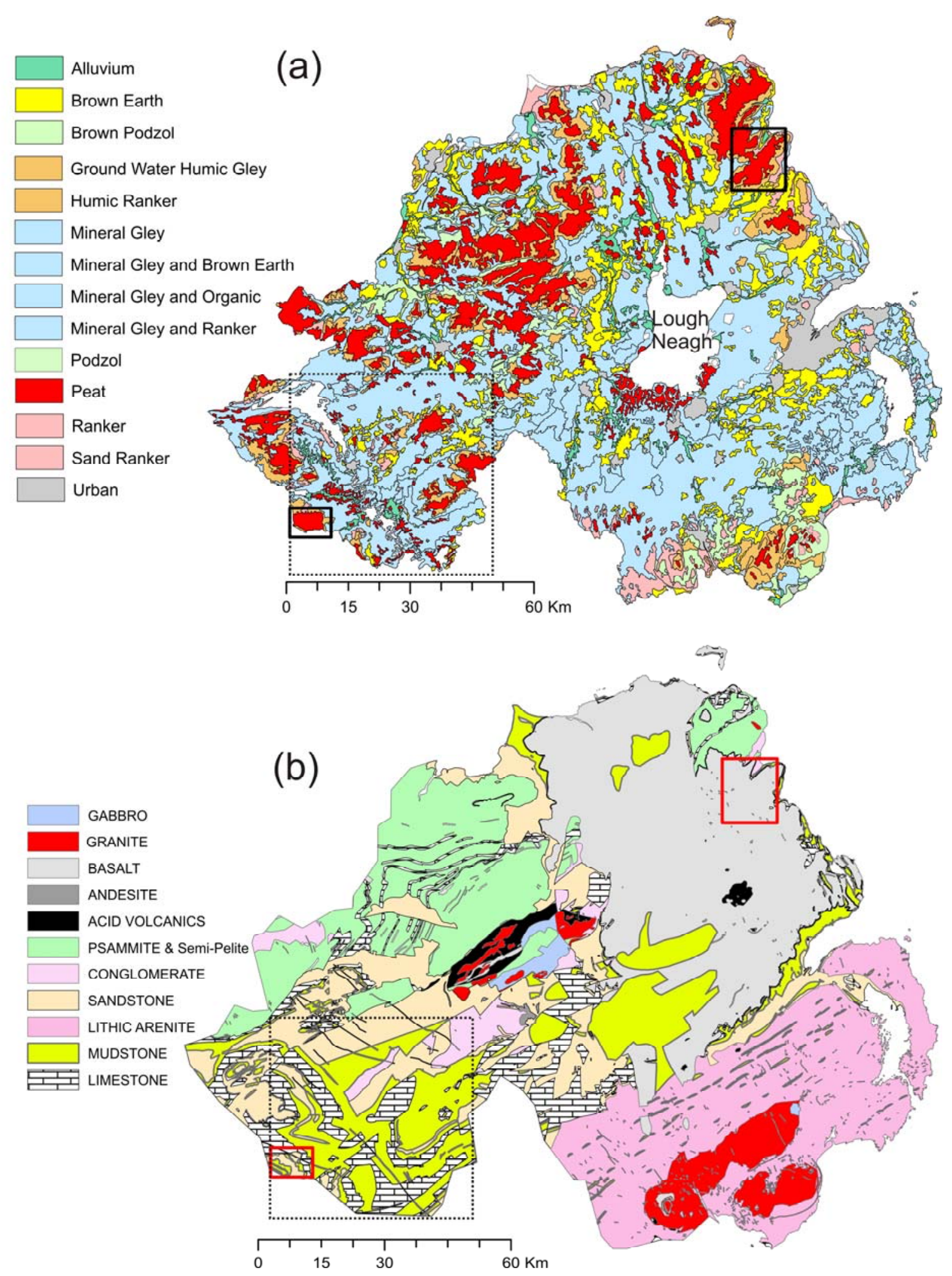

Figure 2 Soil and bedrock maps of Northern Ireland. Three rectangles outline 3 detailed study areas discussed in the text. (a) Soil distribution according to DARD database using a 13-unit (+Urban) soil classification. (b) Simplified 11-unit bedrock classification. 

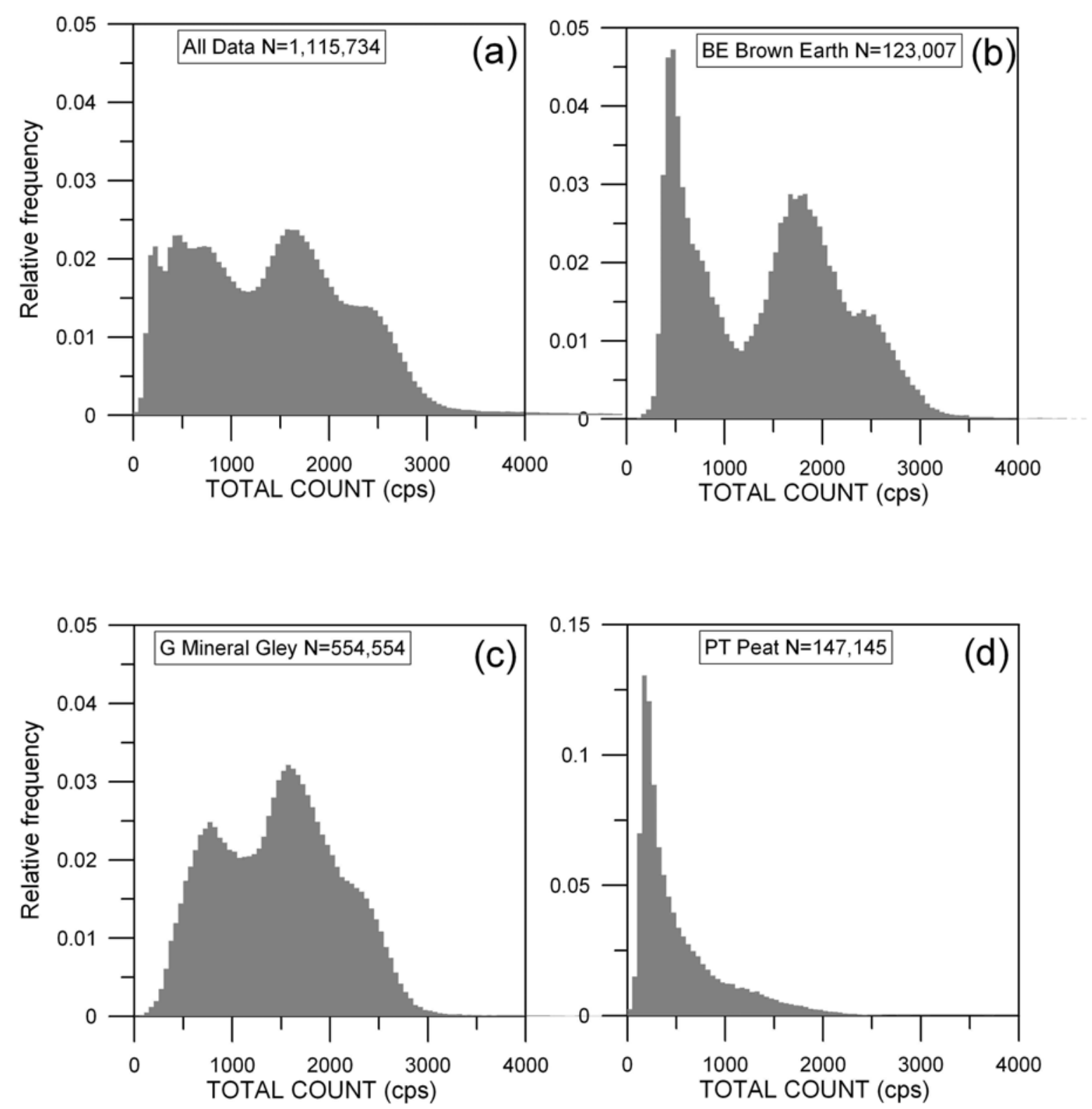

Figure 3 Normalised distributions of the Total Count data for all the data and the 3 major soil types. (a) All data, (b) brown earth (BE), (c) mineral gley (G) and (d) peat (PT). The number of samples (N) is shown for each case. 

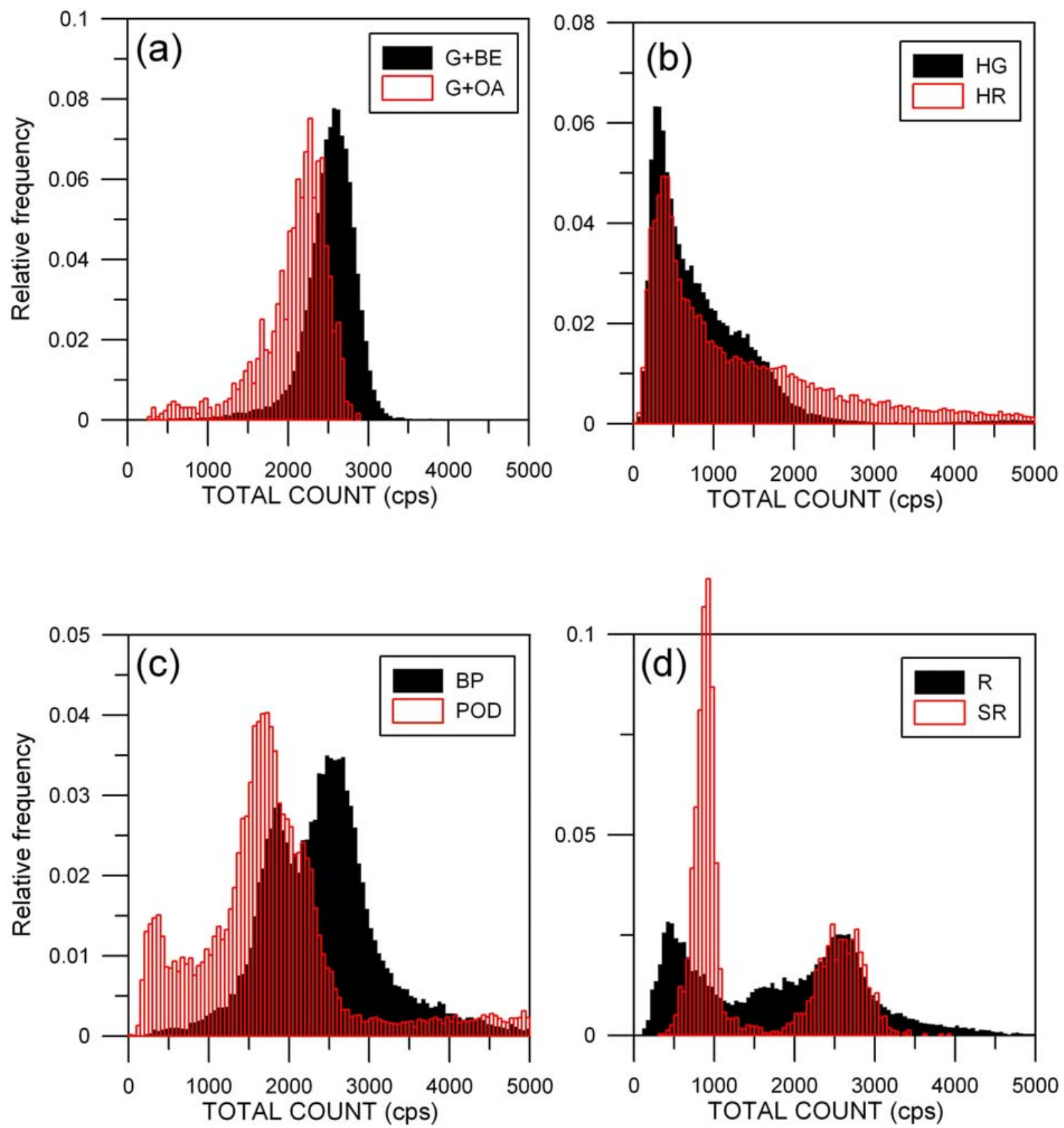

Figure 4 Normalised distributions of the Total Count data for 8 soil types. (a) mineral gley+brown earth $(\mathrm{G}+\mathrm{BE})$ and mineral gley+organic $(\mathrm{G}+\mathrm{OA})$, (b) groundwater humic gley $(\mathrm{HG})$ and humic ranker $(\mathrm{HR})$, (c) brown podzol (BP) and podzol (POD) and (d) ranker (R) and sand ranker. 

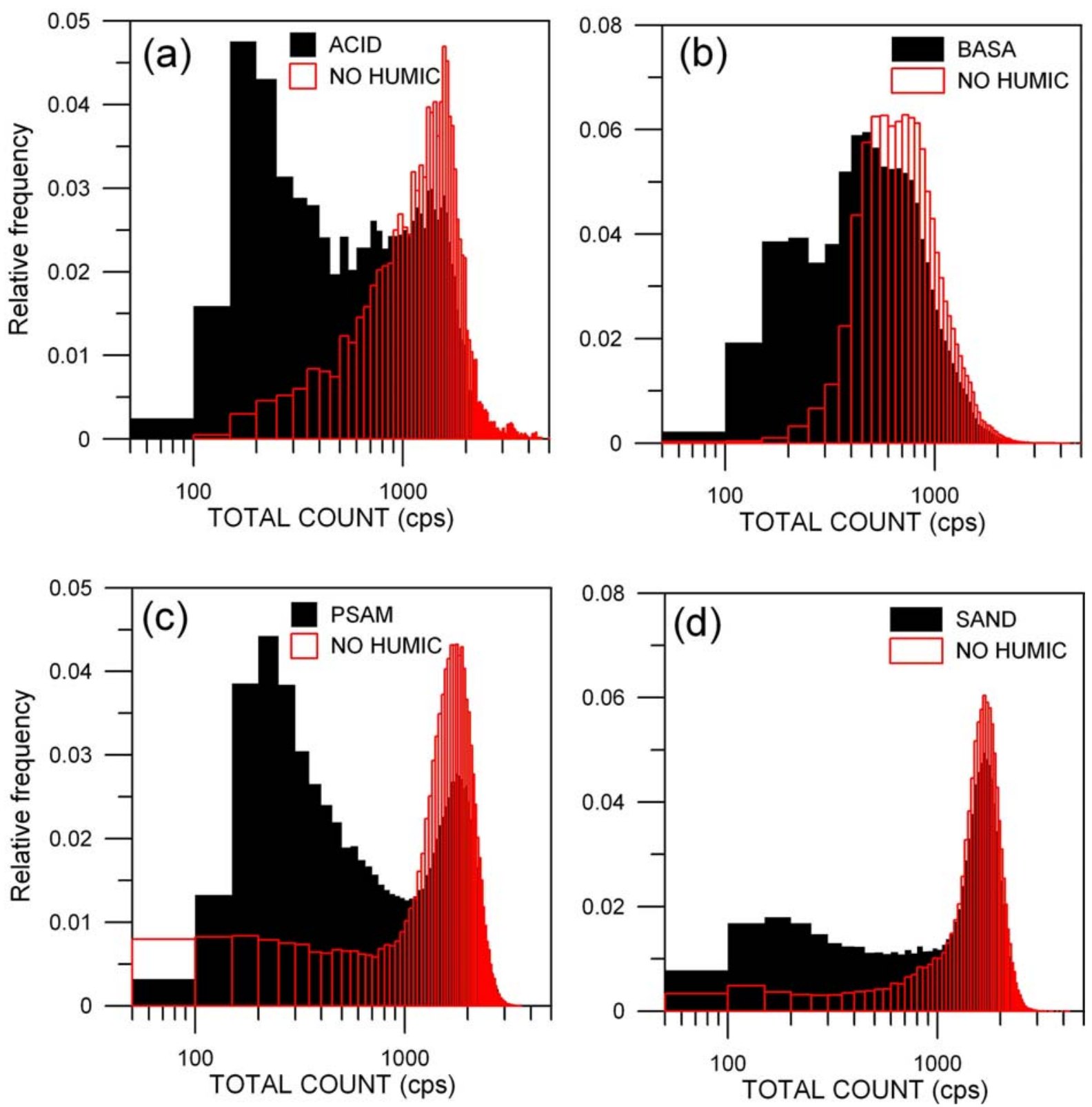

Figure 5 Normalised distributions of the Total Count data (logarithmic scale) for the 4 major bedrock classes, with and without humic soil cover. (a) acid volcanic (ACID), (b) basalt (BASA), (c) psammite (PSAM) and (d) sandstone (SAND). 


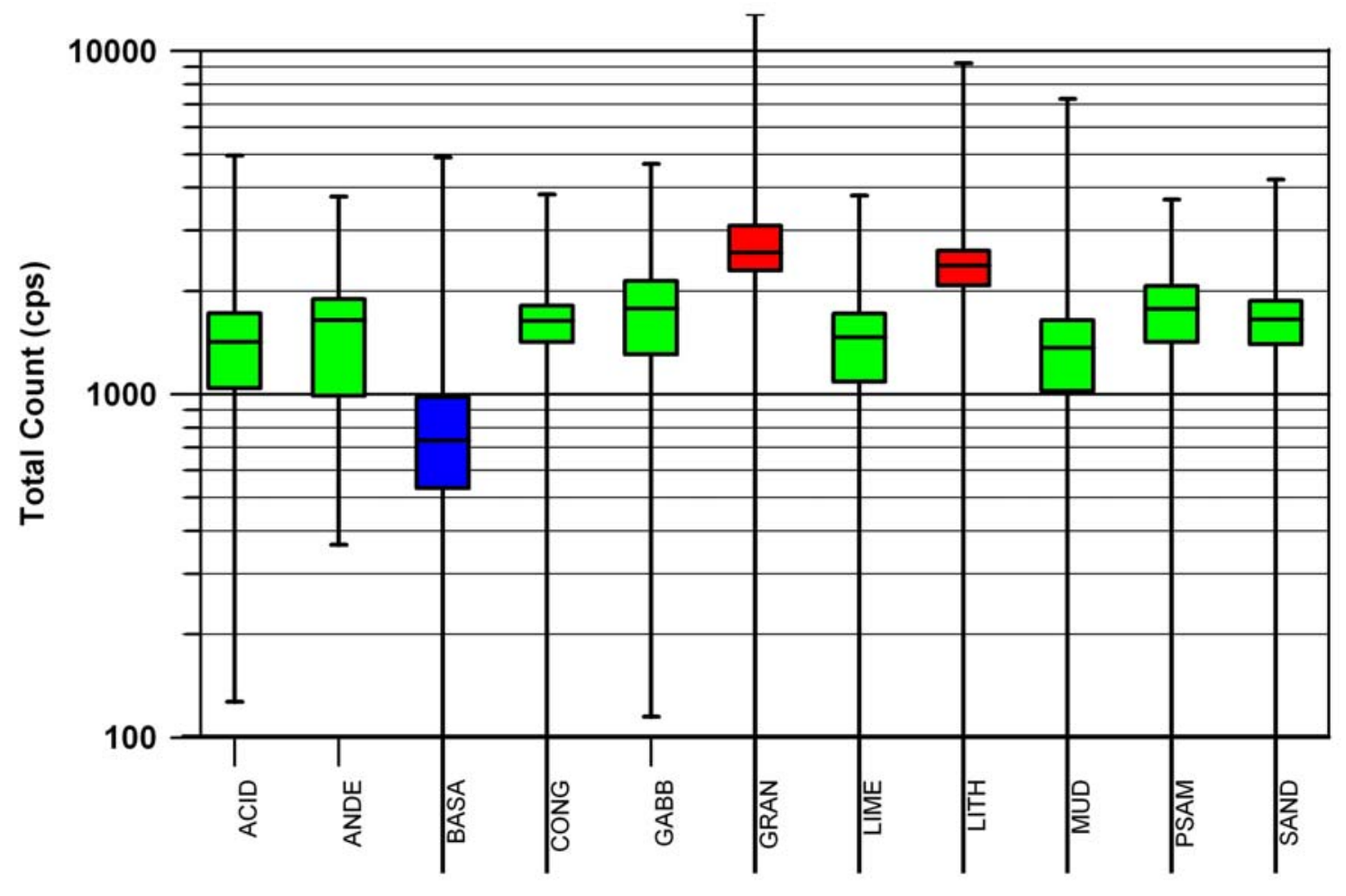

Figure 6 Box and whisker plot summarising the statistical behaviour of the Total Count data (logarithmic scale) classified according to simplified bedrock, and with overlying organic/humic soils omitted. The infilled box indicates the first and third quartiles of each distribution with the enclosed horizontal bar denoting the median value. The terminating bars at the end of each vertical line denote the range of the data. Outliers are omitted. $A C I D=$ acid volcanics, $A N D E=$ andesite,

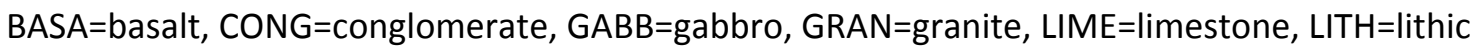
arenite, $\mathrm{MUD}=$ mudstone, $\mathrm{PSAM}=$ psammite + semipelite, $\mathrm{SAND=sandstone.}$ 


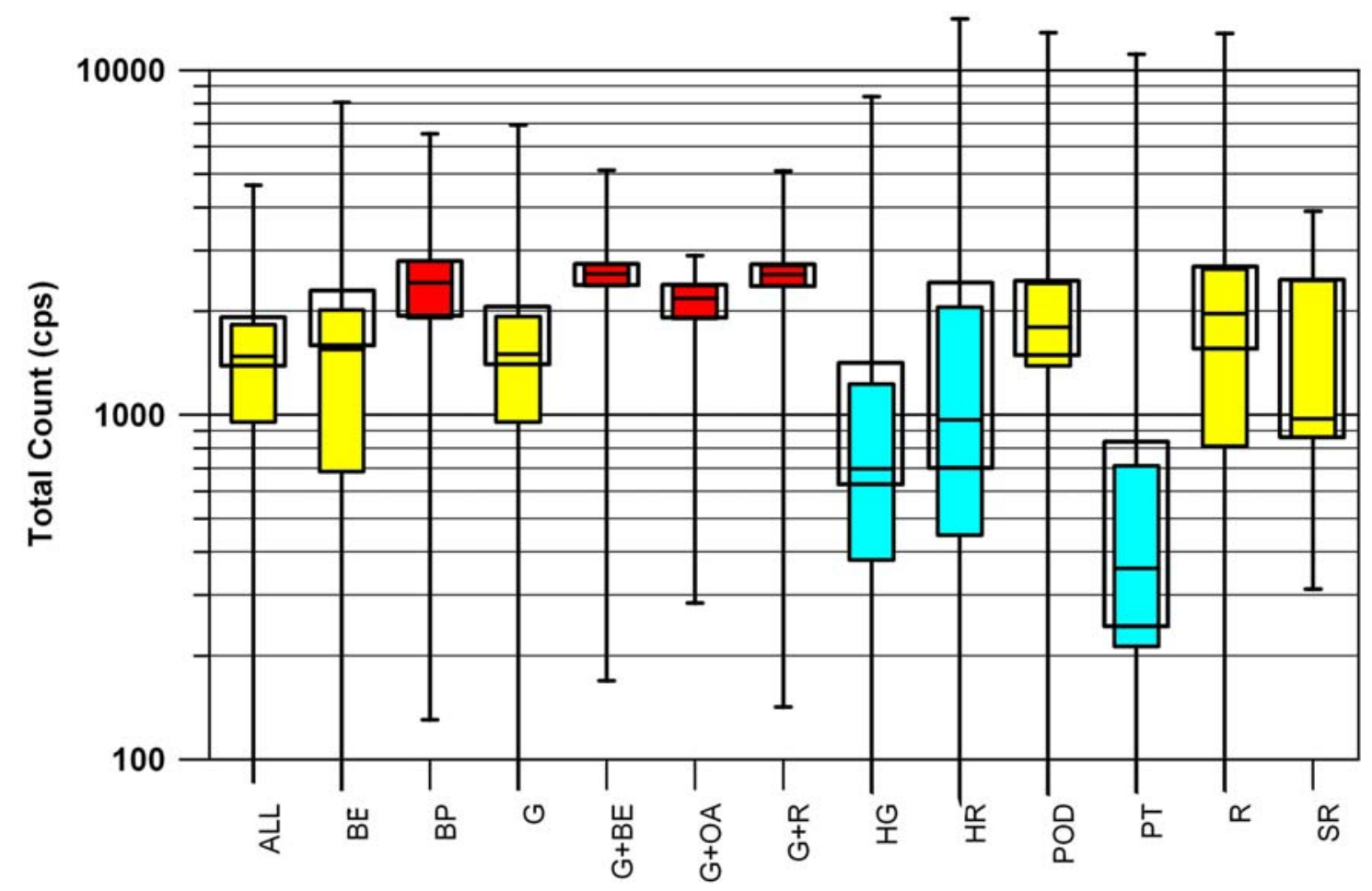

Figure 7 Box and whisker plot summarising the statistical behaviour of the Total Count data (logarithmic scale) classified according to soil type. The larger (open) rectangles indicate the central moments (i.e. first and third quartiles) of the distributions when samples with underlying Basalt bedrock are omitted. $\mathrm{ALL}=$ alluvium, $\mathrm{BE}=$ brown earth, $\mathrm{BP}=$ brown podzol, $\mathrm{G}=$ mineral gley, $\mathrm{G}+\mathrm{BE}=$ mineral gley + brown earth, $\mathrm{G}+\mathrm{OA}=$ mineral gley + organic, $\mathrm{G}+\mathrm{R}=$ mineral gley + ranker, $\mathrm{HG}=$ groundwater humic gley, $\mathrm{POD}=$ podzol, $\mathrm{PT}=$ peat, $\mathrm{R}=$ ranker, $\mathrm{SR}=$ sand ranker. 


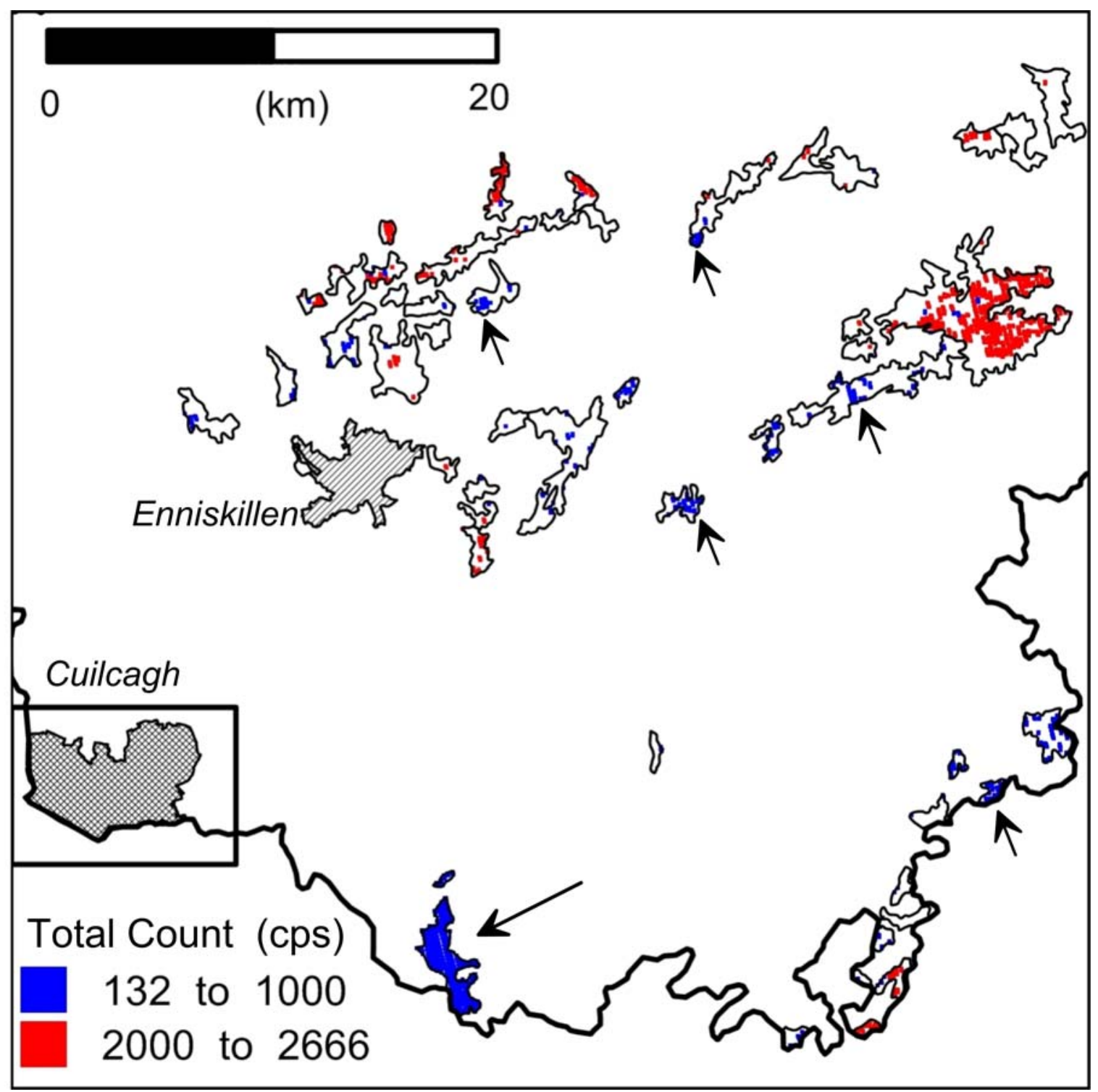

Figure 8 Brown Earth soil distribution (polygons) in the SW of the survey area within a $48 \times 48 \mathrm{~km}$ rectangle. The southern-most line is the border. The values of the Total Count data are shown using two ranges. The low range is from 132 to $1000 \mathrm{cps}$ and the high range is from 2000 to $2666 \mathrm{cps}$. Areas in which natural clusters of low value counts are observed are highlighted with arrows. Two infill areas indicate (i) the town of Enniskillen and (ii) the Cuilcagh Mountain Ramsar site discussed in the text. 


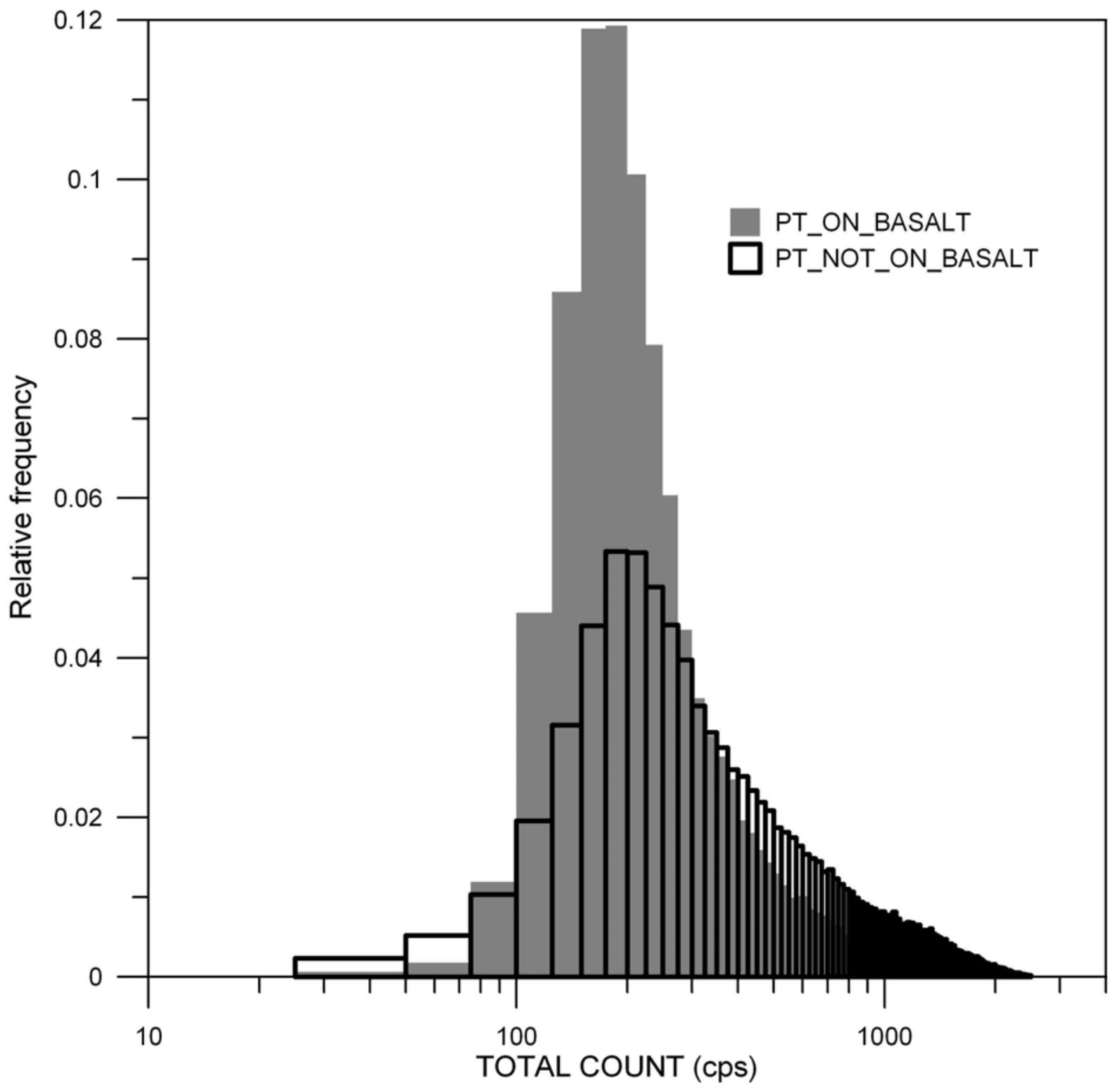

Figure 9 Normalised distributions of the Total Count data (logarithmic scale) for peat on basalt bedrock and peat with no underlying basalt bedrock. 
(a)

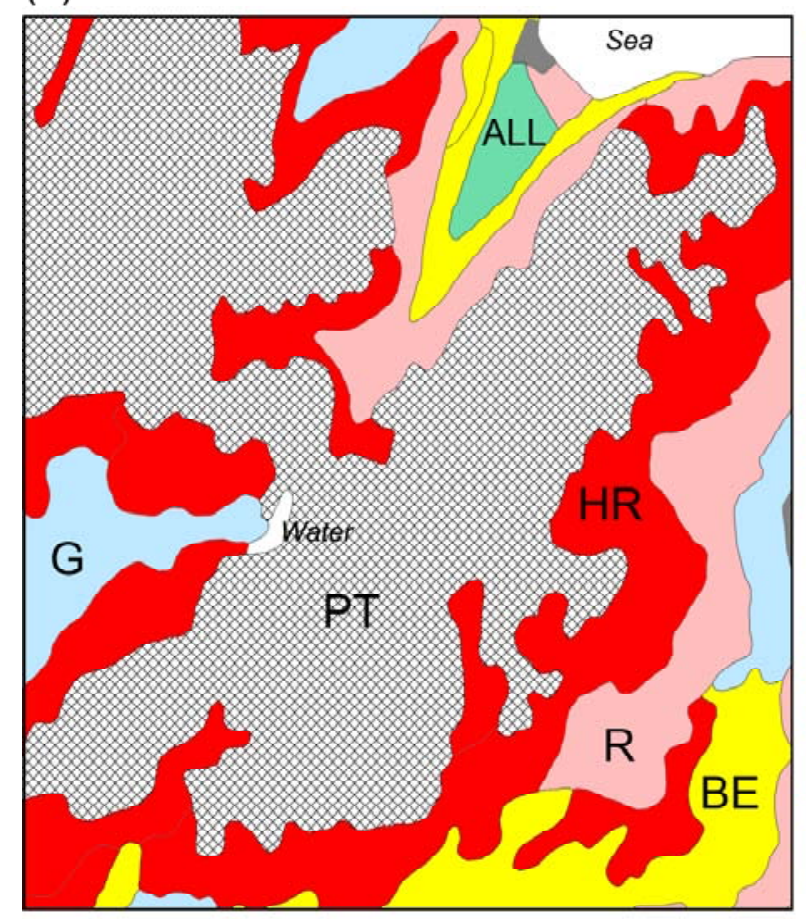

(b)

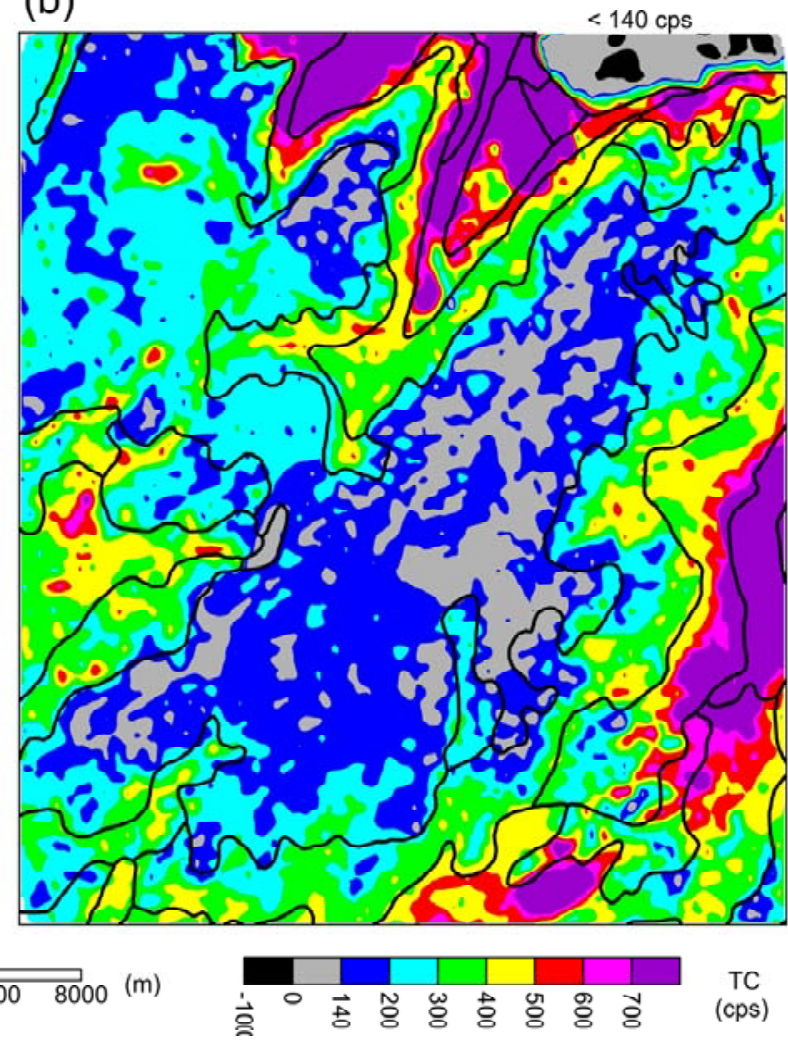

Figure 10 Detailed studies of Total Count data across major blanket bog (Peat) areas. (a) Soil and water distribution across $13 \times 15 \mathrm{~km}$ Garron Plateau area. (b) Total Count (TC) distribution across Garron Plateau area with soil distribution overlaid as lines. The lowest value TC data ( $<140 \mathrm{cps})$ are shown in grey. (c) Soil (DARD) distribution across the $10 \times 7 \mathrm{~km}$ Cuilcagh Mountain area. The data are shown overlaid on an accurate DTM looking due South. The heavy white contour line denotes the DARD classified Peat boundary and the heavy black contour denotes the CORINE classified Peat boundary. An area of no Peat within the DARD database is denoted by ' $A$ ' and a no Peat area within the CORINE database is denoted by ' $B$ '. (d) Total Count (TC) distribution across Cuilcagh Mountain area with Peat boundaries identified with white (DARD) and black (CORINE) heavy contours. 

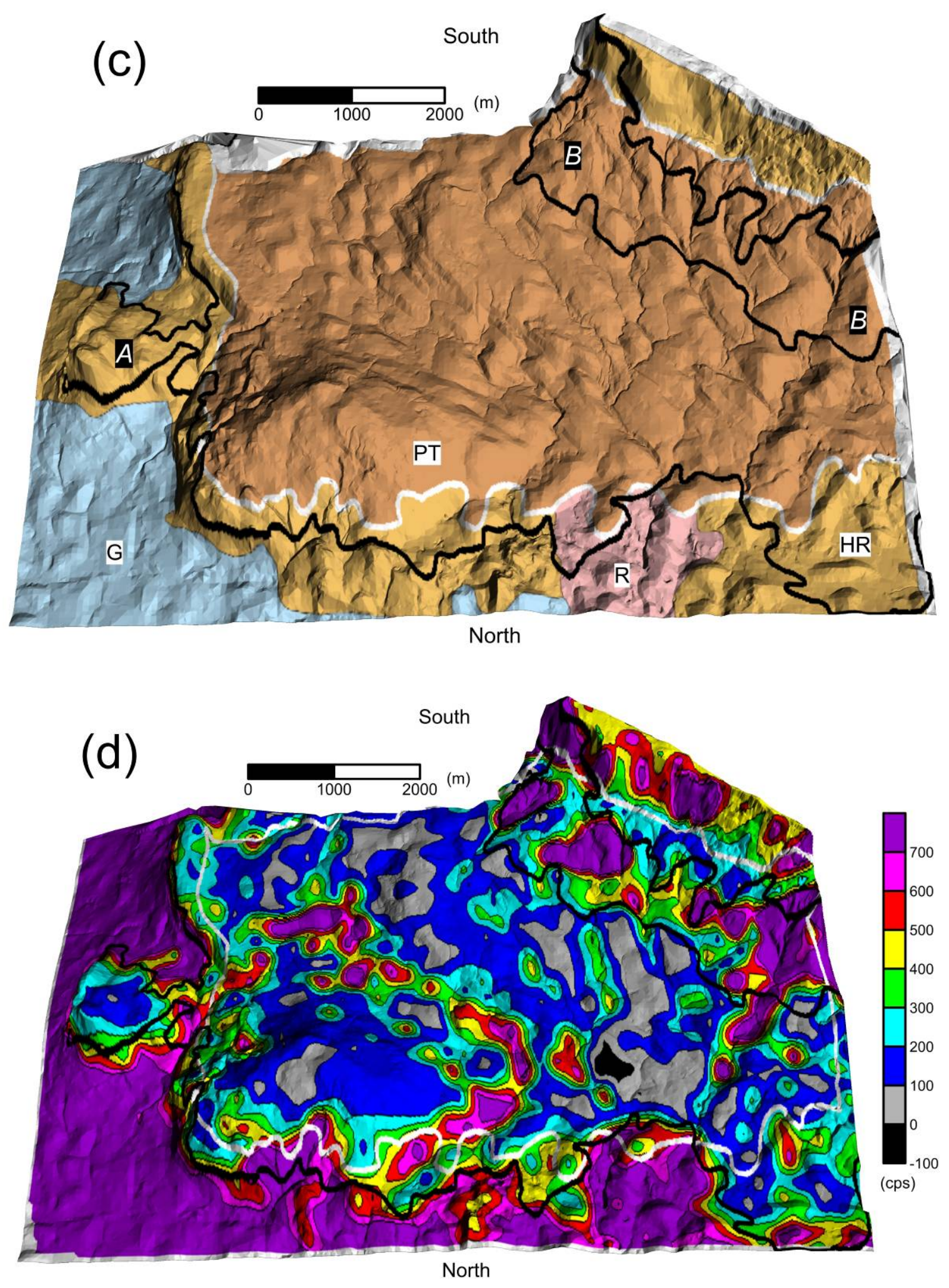

Page $\mathbf{3 7}$ of $\mathbf{3 7}$ 